\title{
ESTUDIO SOBRE EL DERECHO INTERNACIONAL HUMANITARIO CONSUETUDINARIO. UNA CONTRIBUCIÓN A LA COMPRENSIÓN Y AL RESPETO DEL DERECHO DE LOS CONFLICTOS ARMADOS*
}

\author{
Jean-Marie HENCKAERTS**
}

RESUMEN: En este artículo se explican los principios rectores del estudio sobre las normas consuetudinarias del derecho internacional humanitario que realizó el CICR a petición de la Conferencia Internacional de la Cruz Roja y de la Media Luna Roja. Se describen la metodología utilizada y la organización del estudio, y se reseñan los principales resultados, sin entrar en una exposición o análisis detallados.

ABSTRACT: This article explains the rationale behind a study on Customary international humanitarian law recently undertaken by the ICRC at the request of the International Conference of the Red Cross and Red Crescent. It describes the methodology used and how the study was organized, and summarizes some major findings. It does not, however, purport to provide a complete overview or analysis of these findings.

RÉSUMÉ: Cet article expose la raison d'être d'une étude sur le droit International humanitaire coutumier entreprise récemment par le CICR à la demande de la Conférence internationale de la Croix-Rouge et du Croissant-Rouge. Il décrit la méthode utilisée ainsi que la façon dont l'étude a été organisée, et résume quelques-unes de ses principales conclusions, sans prétendre en donner une description complète ni une analyse exhaustive.

* Este texto es la traducción del artículo "Study on customary international humanitarian law: A contribution to the understanding and respect for the rule of law in armed conflict", International Review of the Red Cross, vol. 87, núm. 857, marzo de 2005, pp. 175-212.

** Asesor jurídico en la División Jurídica del CICR y jefe del proyecto de la institución sobre el derecho internacional humanitario consuetudinario. Junto con Louise Doswald-Beck ha dirigido un estudio sobre este derecho, que la editorial Cambridge University Press acaba de publicar en dos volúmenes. El autor desea agradecer a Eric Mongelard la ayuda que le ha prestado en la preparación de este artículo, así como a Louise Doswald-Beck y a los colegas de la División Jurídica sus perspicaces comentarios. Las consideraciones expuestas en el presente artículo reflejan las opiniones del autor, y no necesariamente las del CICR. 
SUMARIO: I. Introducción. II. Finalidad del estudio. III. Metodología aplicada. IV. Organización del estudio. V. Resumen de los resultados. VI. Conclusión. VII. Anexo.

\section{INTRODUCCIÓN}

En los más de cincuenta años transcurridos desde la aprobación de los Convenios de Ginebra de 1949, la humanidad ha sido testigo de una proliferación alarmante de los conflictos armados que han afectado prácticamente a todos los continentes. Durante ese tiempo, los cuatro Convenios de Ginebra y sus dos protocolos adicionales de 1977 han proporcionado protección jurídica a las personas que no participan o han dejado de participar directamente en las hostilidades (los heridos, los enfermos y los náufragos, así como las personas privadas de libertad por razones relacionadas con el conflicto armado y la población civil). Aun así, se han cometido numerosas violaciones de esos tratados, que ocasionaron muertes y sufrimientos que se podrían haber evitado si se hubiera respetado en mayor medida el derecho internacional humanitario.

La opinión general es que las violaciones del derecho internacional humanitario no se deben a la inadecuación de sus normas, sino más bien a la escasa voluntad de respetarlas, a la falta de medios para hacerlas cumplir, a la inseguridad sobre su aplicación en algunas circunstancias y a su desconocimiento por parte de los dirigentes políticos, jefes militares, combatientes y público en general.

En la Conferencia Internacional para la Protección de las Víctimas de la Guerra, celebrada en Ginebra, del 30 de agosto al 1o. de septiembre de 1993, se debatieron en particular los medios y las maneras de afrontar las violaciones del derecho internacional humanitario, pero no se propuso la aprobación de nuevas disposiciones convencionales. En cambio, en la declaración final, aprobada por consenso, la conferencia reafirmó "la necesidad de reforzar la eficacia de la aplicación del derecho internacional humanitario" y solicitó al gobierno suizo que reuniera "un grupo intergubernamental de expertos de composición no limitada encargado de dar con los medios prácticos para promover el pleno respeto de este derecho y la aplicación de sus normas, así como de preparar un informe para 
los Estados y para la próxima Conferencia Internacional de la Cruz Roja y de la Media Luna Roja". ${ }^{1}$

Este Grupo Intergubernamental de Expertos para la Protección de las Víctimas de la Guerra se reunió en Ginebra, en enero de 1995, y adoptó una serie de recomendaciones destinadas a reforzar el respeto del derecho internacional humanitario, en particular mediante medidas preventivas para mejorar su conocimiento y hacer más eficaz su aplicación. En la Recomendación II, el Grupo Intergubernamental de Expertos propuso que:

Se invite al CICR a elaborar, con la asistencia de expertos en derecho internacional humanitario que representen a diversas regiones geográficas y distintos sistemas jurídicos, y en consulta con expertos de gobiernos y organizaciones internacionales, un informe sobre las normas consuetudinarias del derecho internacional humanitario aplicables en conflictos armados internacionales y de otra índole, y a que distribuya este informe a los Estados y a los organismos internacionales competentes . ${ }^{2}$

En diciembre de 1995, la XXVI Conferencia Internacional de la Cruz Roja y de la Media Luna Roja refrendó esta recomendación y encargó oficialmente al CICR que preparara un informe sobre las normas consuetudinarias del derecho internacional humanitario aplicables en los conflictos armados internacionales y no internacionales. ${ }^{3}$ Casi diez años después, en 2005, tras una minuciosa investigación y numerosas consultas a expertos, se ha publicado este informe, al que se hace referencia en

1 "Conferencia Internacional para la Protección de las Víctimas de la Guerra, 30 de agosto-10. de septiembre de 1993, Declaración Final”, Revista Internacional de la Cruz Roja (RICR), núm. 119, septiembre-octubre de 1993, p. 398.

2 "Reunión del Grupo Intergubernamental de Expertos para la Protección de las Víctimas de la Guerra, Ginebra, 23-27 de enero de 1995, Recomendación II", RICR, núm. 133, 1996. Disponible en: www.cicr.org/spa, sección "Recursos Informativos", subsección "Revista Internacional".

3 "XXVI Conferencia Internacional de la Cruz Roja y de la Media Luna Roja, Ginebra, 3-7 de diciembre de 1995, Resolución 1, Derecho internacional humanitario: del derecho a la acción; Informe sobre el seguimiento de la Conferencia Internacional para la Protección de las Víctimas de la Guerra", RICR, núm. 133, 1996. Disponible en: www.cicr.org/spa, sección "Recursos informativos", subsección "Revista internacional". 
adelante como Estudio sobre el derecho internacional humanitario consuetudinario. ${ }^{4}$

\section{FINALIDAD DEL ESTUDIO}

La finalidad del Estudio sobre el derecho internacional humanitario consuetudinario era superar algunos de los problemas que plantea la aplicación del derecho internacional humanitario convencional. Este derecho, que está bien desarrollado y cubre numerosos aspectos de la guerra, brinda protección a diversas categorías de personas en tiempo de guerra, y limita los medios y métodos bélicos permitidos. Los Convenios de Ginebra y sus protocolos adicionales contienen una amplia normativa para la protección de las personas que no participan o han dejado de participar en las hostilidades. La regulación de los medios y métodos de guerra en el derecho convencional se remonta a la Declaración de San Petersburgo de 1868, a los Reglamentos de La Haya de 1899 y 1907 y al Protocolo de Ginebra de 1925 sobre Gases Asfixiantes. Más tarde se abordó esta cuestión en la Convención de 1972 sobre Armas Biológicas, los protocolos adicionales de 1977, la Convención de 1980 sobre Ciertas Armas Convencionales y sus cinco protocolos, la Convención de 1993 sobre Armas Químicas y la Convención de Ottawa de 1997 sobre la Prohibición de las Minas Antipersonal. La protección de los bienes culturales en caso de conflicto armado está regulada en detalle por la Convención de La Haya de 1954 y sus dos protocolos. El Estatuto de 1998 de la Corte Penal Internacional contiene, entre otras cosas, una lista de crímenes de guerra sometidos a su jurisdicción.

Ahora bien, la aplicación de esos tratados en los conflictos armados actuales tropieza con dos graves impedimentos que explican la necesidad y la conveniencia de un estudio sobre las normas consuetudinarias del derecho internacional humanitario. En primer lugar, los tratados se aplican solamente a los Estados que los han ratificado, lo que significa que los distintos tratados de derecho internacional humanitario se aplican a los diferentes conflictos armados, según qué tratados hayan suscrito los Estados implicados. Si la ratificación de los cuatro Convenios de Gine-

4 Henckaerts, Jean-Marie y Doswald-Beck, Louise, Derecho internacional humanitario consuetudinario, vol. I: Normas y vol. II: Practice, Cambridge University Press, 2005. 
bra es universal, no puede decirse lo mismo de otros instrumentos de derecho humanitario, como son sus protocolos adicionales. A pesar de que el Protocolo adicional I ha sido ratificado por más de 160 Estados, tiene hoy una eficacia limitada, puesto que varios Estados que han estado implicados en conflictos armados internacionales no son partes en él. Del mismo modo, aunque unos 160 Estados han ratificado el Protocolo adicional II, varios Estados en cuyo territorio se libran conflictos armados no internacionales no lo han hecho. A menudo, la única disposición del derecho humanitario convencional aplicable en este tipo de conflictos es el artículo 3 común a los cuatro Convenios de Ginebra. Así pues, la primera finalidad del estudio era determinar qué normas del derecho internacional humanitario forman parte del derecho internacional consuetudinario $\mathrm{y}$, por ende, son aplicables a todas las partes en un conflicto, hayan ratificado o no los tratados que contienen esas normas u otras similares.

En segundo lugar, el derecho humanitario convencional no regula con suficiente detalle gran parte de los conflictos armados actuales, es decir, los conflictos armados no internacionales, porque estos conflictos están sujetos a muchas menos normas convencionales que los conflictos internacionales. Sólo un número limitado de tratados son aplicables a los conflictos armados no internacionales, a saber: la Convención sobre Ciertas Armas Convencionales (enmendada), el Estatuto de la Corte Penal Internacional, la Convención de Ottawa sobre la Prohibición de las Minas Antipersonal, la Convención sobre Armas Químicas, la Convención de La Haya para la Protección de los Bienes Culturales y su Protocolo II y, como acabamos de señalar, el Protocolo adicional II y el artículo 3 común a los cuatro Convenios de Ginebra. Aunque el artículo 3 común tiene una importancia fundamental, sólo proporciona un marco rudimentario de exigencias mínimas. El Protocolo adicional II es un complemento útil del artículo 3 común, pero es menos detallado que las normas que rigen los conflictos armados internacionales contenidas en los Convenios de Ginebra y en el Protocolo adicional I.

El Protocolo adicional II apenas contiene 15 artículos sustantivos, mientras que el Protocolo adicional I tiene más de 80. Aunque las meras cifras no lo dicen todo, revelan una diferencia significativa acerca de cómo el derecho convencional regula los conflictos armados internacionales y los no internacionales, sobre todo por lo que respecta a las normas detalladas y las definiciones. Por eso, la segunda finalidad del estu- 
dio era determinar si el derecho internacional consuetudinario regula los conflictos armados no internacionales de manera más detallada que el derecho convencional y, en caso afirmativo, en qué medida.

\section{METODOLOGÍA APLICADA}

El Estatuto de la Corte Internacional de Justicia define el derecho consuetudinario como "una práctica generalmente aceptada como derecho". 5 Se acepta en general que la existencia de una norma de derecho internacional consuetudinario requiere la presencia de dos elementos, a saber, la práctica estatal (usus) y la creencia de que esa práctica se exige, se prohíbe o se permite, según la índole de la norma, como derecho (opinio juris sive necessitatis). Como la Corte Internacional de Justicia afirmó en el asunto Continental Shelf, "es naturalmente axiomático que la materia del derecho internacional consuetudinario hay que buscarla ante todo en la práctica efectiva y en la opinio juris de los Estados". ${ }^{6}$ El significado exacto y el contenido de estos dos elementos han sido objeto de muchos escritos eruditos. El modo de proceder seguido en este estudio para determinar si existe una norma de derecho internacional consuetudinario general responde a un planteamiento clásico, expuesto por la Corte Internacional de Justicia en varias causas, en particular en los asuntos North Sea Continental Shelf . ${ }^{7}$

\section{La práctica de los Estados}

La práctica de los Estados debe contemplarse desde dos puntos de vista: en primer lugar, para determinar qué práctica contribuye a la creación de derecho internacional consuetudinario (selección de la práctica estatal) y, en segundo lugar, para examinar si establece una norma de ese derecho (evaluación de la práctica estatal).

\section{A. Selección de la práctica de los Estados}

Las actuaciones de los Estados, tanto las materiales o de obra como las verbales o de palabra, contribuyen a la creación de derecho interna-

5 Estatuto de la Corte Internacional de Justicia (CIJ), artículo 38 (1) (b).

6 CIJ, Continental Shelf case (Libyan Arab Jamahiriya vs. Malta), fallo, 3 de junio de 1985, ICJ Reports 1985, pp. 29 y 30, párr. 27.

7 CIJ, North Sea Continental Shelf cases, fallo, 20 de febrero de 1969, ICJ Reports 1969 , p. 3. 
cional consuetudinario. Las actuaciones materiales comprenden, por ejemplo, el comportamiento en el campo de batalla, el empleo de ciertas armas y el trato dispensado a distintas categorías de personas. Las actuaciones verbales incluyen los manuales militares, las leyes internas, la jurisprudencia nacional, las instrucciones a las fuerzas armadas y de seguridad, los comunicados militares durante una guerra, las notas diplomáticas de protesta, las opiniones de asesores jurídicos oficiales, los comentarios de los gobiernos sobre proyectos de tratados, las decisiones y los reglamentos ejecutivos, los alegatos ante tribunales internacionales, las declaraciones en organismos y conferencias internacionales y las tomas de posición de los gobiernos en relación con resoluciones de organizaciones internacionales. Esta lista muestra que la práctica de los organismos ejecutivos, legislativos y judiciales de un Estado puede contribuir a la creación de derecho internacional consuetudinario.

La negociación y la aprobación de resoluciones por organizaciones o por conferencias internacionales, junto con las explicaciones de los votos, son actuaciones que implican a los Estados. Se reconoce, con pocas excepciones, que las resoluciones no son normalmente vinculantes en sí mismas y, por ende, el valor que se concede a cada resolución en particular depende de su contenido, de su grado de aceptación y de la coherencia con la restante práctica del Estado. ${ }^{8}$ Cuanto mayor sea el apoyo a la resolución, más importancia hay que darle.

Aunque las decisiones de los tribunales internacionales son fuentes subsidiarias de derecho internacional, ${ }^{9}$ no constituyen práctica de $10 \mathrm{~s}$ Estados, puesto que dichas instancias, a diferencia de los tribunales nacionales, no son órganos estatales. No obstante, sus decisiones se han incluido en el estudio, porque el fallo de un tribunal internacional en el sentido de que existe una norma de derecho internacional consuetudinario constituye una prueba convincente al respecto. Además, debido al valor jurisprudencial de sus decisiones, los tribunales internacionales pueden también contribuir a la aparición de normas de derecho internacional consuetudinario, influenciando así la práctica subsiguiente de los Estados y las organizaciones internacionales.

8 La CIJ resaltó la importancia de estas condiciones en el Legality of the Threat or Use Nuclear Weapons, opinión consultiva, 8 de julio de 1996, ICJ Reports 1996, pp. 254 y 255 , párrs. $70-73$.

9 Estatuto de la CIJ, artículo 38 (1) (d). 
La práctica de los grupos armados de oposición, tales como códigos de conducta, compromisos adquiridos de observar ciertas normas del derecho internacional humanitario y otras declaraciones, no constituyen, en sí, práctica estatal. Aunque esas prácticas pueden contener pruebas de la aceptación de ciertas normas en los conflictos armados no internacionales, su significación jurídica no está clara, por lo cual no pueden considerarse como prueba de la existencia de derecho internacional consuetudinario. En la sección "Otras prácticas" del volumen II del estudio se cita una serie de ejemplos a este respecto.

\section{B. Evaluación de la práctica estatal}

Para determinar si la práctica de los Estados es lo suficientemente "densa" como para crear una norma de derecho internacional consuetudinario, hay que analizarla. ${ }^{10}$ Para establecer una norma de derecho internacional consuetudinario, la práctica estatal ha de ser prácticamente uniforme, extensa y representativa. ${ }^{11}$ Pero veamos más detenidamente lo que esto significa.

El primer requisito para que la práctica de los Estados cree una norma de derecho internacional consuetudinario es que sea prácticamente uniforme. Diferentes Estados no tienen que haberse comportado de manera sustancialmente distinta. La jurisprudencia de la Corte Internacional de Justicia muestra que una práctica contraria, que a primera vista parece minar dicha uniformidad, no impide la formación de una norma de derecho internacional consuetudinario, siempre que esa práctica contraria la condenen otros Estados o la rechace el propio gobierno. Tales condenas o rechazos confirman de hecho la norma en cuestión. ${ }^{12}$

Esto es particularmente pertinente para una serie de normas de derecho internacional humanitario en las que, junto a la abrumadora evidencia de que la práctica verbal de los Estados las respalda, hay reiteradas pruebas de violaciones de esas normas. Cuando estas infracciones han

10 El término "densa", en este contexto, procede de sir Humphrey Waldock, "General Course on Public International Law", Collected Courses of the Hague Academy of International Law, vol. 106, 1962, p. 44.

11 CIJ, North Sea..., cit., nota 7, p. 43, párr. 74.

12 Véase CIJ, Case concerning Military and Paramilitary Activities in and against Nicaragua (Nicaragua vs. United States), fondo, fallo, 27 de junio de 1986, ICJ Reports 1986, p. 98, párr. 186. 
ido acompañadas de excusas o justificaciones de los actores y/o de condenas de otros Estados, no son de tal índole que pongan en duda la existencia de la norma en cuestión. Los Estados que deseen cambiar una norma de derecho internacional consuetudinario vigente han de hacerlo mediante su práctica oficial y declarar que están actuando de derecho.

El segundo requisito para que se establezca una norma de derecho internacional consuetudinario general es que la práctica estatal concernida sea extensa y representativa. No necesita, en cambio, ser universal; es suficiente una práctica "general". ${ }^{13}$ No se requiere un número o porcentaje exacto de Estados. Una de las razones por las que es imposible precisar la participación requerida es que este criterio es en cierto modo cualitativo, más que cuantitativo. Es decir, que no es una mera cuestión de cuántos Estados participan en la práctica, sino también de qué Estados. ${ }^{14}$ Como señaló la Corte Internacional de Justicia en los asuntos North Sea Continental Shelf, la práctica ha de "incluir los Estados cuyos intereses resulten especialmente afectados". ${ }^{15}$

Estas consideraciones tienen dos consecuencias: 1) Si están representados todos los "Estados especialmente afectados", no es fundamental para la mayoría de los Estados haber participado activamente, pero tienen que haber asentido al menos a la práctica de los "Estados especialmente afectados"; 2) Si los "Estados especialmente afectados" no aceptan la práctica, ésta no puede cristalizar en una norma de derecho internacional consuetudinario, aún cuando no se requiera, como se ha explicado, que haya unanimidad. ${ }^{16}$ Quién está "especialmente afectado", a la luz del derecho internacional humanitario, variará según las circunstancias. Por lo que atañe a la cuestión de la legalidad del empleo de las armas láser que causan ceguera, por ejemplo, los "Estados especialmente afectados" incluyen los Estados identificados por su participación en el desarrollo de tales armas, aunque sean otros Estados los que puedan sufrir las consecuencias de su uso. Del mismo modo, en el ámbito de la ayuda humanitaria, los Estados cuya población necesita esa ayuda o los

13 ILA, Informe final del Comité para la Formación de Derecho Internacional Consuetudinario (general), Declaración de Principios Aplicables a la Formación del Derecho Internacional Consuetudinario General, Report of the Sixty-Ninth Conference, Londres, 2000, principio 14, pp. 734 (en adelante, ILA Report).

14 Ibidem, comentarios (d) y (e) del principio 14, pp. 736 y 737.

15 CIJ, North Sea..., cit., nota 7, p. 43, párr. 74.

16 ILA Report, cit., nota 13, comentario (e) del principio 14, p. 737. 
que suelen prestarla han de ser considerados como "especialmente afectados". Por lo que respecta a cualquier norma del derecho internacional humanitario, los países que participan en un conflicto armado son "especialmente afectados" cuando su práctica examinada en relación con una norma determinada estaba relacionada con ese conflicto. Si bien es verdad que puede haber Estados especialmente afectados en determinados ámbitos del derecho internacional humanitario, es asimismo cierto que todos los Estados tienen un interés legal en exigir que otros Estados respeten el derecho internacional humanitario, aunque no sean parte en el conflicto. ${ }^{17}$ Además, todos los Estados pueden ser víctimas de medios y métodos de guerra empleados por otros Estados. Por ello, hay que examinar la práctica de todos los Estados, tanto si están "especialmente afectados" en sentido estricto, como si no lo están.

En el presente estudio no se ha tomado en consideración si es legalmente posible ser un "objetor habitual" en relación con las normas consuetudinarias del derecho internacional humanitario. Muchos tratadistas creen que no es posible en el caso de las normas de jus cogens, pero hay otros que dudan de que el concepto de objetor habitual siga siendo válido. ${ }^{18} \mathrm{Si}$ se acepta que es legalmente posible ser un objetor habitual, el Estado concernido tiene que haber recusado la aceptación de una nueva norma durante su formación y seguir impugnándola después; no es posible ser un "objetor posterior". ${ }^{19}$

Si bien es cierto que normalmente transcurre algún tiempo hasta que la práctica que satisfaga esos criterios sea suficiente, no existe un requisito específico de tiempo. Todo es cuestión de acumular una práctica de suficiente densidad, en términos de uniformidad, extensión y representatividad. ${ }^{20}$

\section{Opinio juris}

El segundo requisito para la existencia de una norma de derecho internacional consuetudinario, la opinio juris, se relaciona con la necesidad

17 Véase op. cit., nota 4, vol. I, comentario de la norma 144.

18 Para un examen a fondo de esta cuestión, véase Mendelson, Maurice H., "The Formation of Customary International Law", Collected Courses of the Hague Academy of International Law, vol. 272, 1998, pp. 227-244.

19 ILA Report, cit., nota 13, comentario (b) del principio 15, p. 738.

20 Ibidem, comentario (b) del principio 12, p. 731. 
de que la práctica se lleve a cabo "de derecho". La forma en que la práctica y esta convicción jurídica han de expresarse puede tal vez diferir según que la norma concernida contenga una prohibición, una obligación o sólo el derecho a comportarse de cierta manera.

Durante la realización del estudio, resultó muy difícil, y en gran medida un empeño teórico, separar estrictamente los elementos de la práctica y la convicción jurídica. Lo más frecuente es que la misma actuación plasme la práctica y la convicción jurídica. Como ha señalado la Asociación de Derecho Internacional, la Corte Internacional de Justicia "no ha dicho de manera explícita que, porque hay (presuntamente) distintos elementos en el derecho consuetudinario, el mismo comportamiento no puede manifestar ambas cosas. De hecho es a menudo difícil, si no imposible, desenredar los dos elementos". ${ }^{21}$ Eso es, en particular, así porque las actuaciones verbales se consideran como práctica de los Estados, que suelen reflejar, al mimo tiempo, la convicción jurídica del Estado concernido.

Cuando hay una práctica suficientemente densa, ésta contiene en general una opinio juris, por lo cual no suele ser necesario demostrar separadamente su existencia. Cuando la práctica es ambigua, la opinio juris desempeña, en todo caso, un importante papel a la hora de decidir si ha de tenerse o no en cuenta para la formación de la costumbre. Así ocurre a menudo con las omisiones, cuando los Estados se abstienen de actuar o reaccionar, sin que esté claro por qué. Es en tales casos en los que tanto la Corte Internacional de Justicia como su predecesor, el Tribunal Permanente de Justicia Internacional, han intentado establecer separadamente la existencia de una opinio juris, con el fin de determinar si esa práctica ambigua debía tenerse efectivamente en cuenta para tipificar normas de derecho internacional consuetudinario. ${ }^{22}$

21 Ibidem, p. 718, párr. 10 (c). Para un análisis más a fondo de esta cuestión, véase Haggenmacher, Peter, "La doctrine des deux éléments du droit coutumier dans la pratique de la Cour internationale", Revue Générale de Droit International Public, vol. 90, 1986 , p. 5.

22 Véase, por ejemplo, el Tribunal Permanente de Justicia Internacional, Lotus case (France vs. Turkey), fallo, 7 de septiembre de 1927, PCIJ Ser. A., núm. 10, p. 28 (el tribunal concluyó que los Estados no se habían abstenido de enjuiciar los comportamientos ilícitos cometidos a bordo de los navíos porque creían que les estaba prohibido hacerlo); CIJ, North Sea..., cit., nota 7, pp. 43 y 44, párrs. 76 y 77 (la corte estimó que los Estados que habían delimitado su plataforma continental basándose en el principio de equidis- 
En el ámbito del derecho internacional humanitario, en el que muchas normas requieren abstenerse de ciertos comportamientos, las omisiones plantean un problema particular en la tarea de determinar la opinio juris, ya que ha de probarse que la abstención no es una coincidencia, sino que está basada en una expectativa legítima. Cuando esa exigencia de abstenerse se indica en instrumentos internacionales y en declaraciones oficiales, generalmente puede probarse la existencia de un requisito legal de abstenerse del comportamiento en cuestión. Además, tales abstenciones pueden también producirse después de que ese comportamiento haya provocado cierta controversia, lo que contribuye asimismo a probar que la abstención no era una coincidencia, aunque no siempre sea fácil concluir que se ha producido por el sentido del deber legal.

\section{Influencia del derecho convencional}

Los tratados también son pertinentes en la determinación de la existencia del derecho internacional consuetudinario, porque ayudan a evaluar qué opinan los Estados de ciertas normas del derecho internacional. Por eso, se han incluido en el estudio la ratificación, la interpretación y la aplicación de los tratados, así como las reservas y las declaraciones de interpretación efectuadas antes de ratificarlos. En las causas de la North Sea Continental Shelf, la Corte Internacional de Justicia señaló claramente que el grado de ratificación de un tratado es importante para evaluar el derecho consuetudinario. En ese caso, la corte declaró que "el número de ratificaciones y adhesiones alcanzado hasta ahora [39], aunque sea respetable, apenas es suficiente", especialmente en un contexto en el que la práctica no sujeta al tratado es contradictoria. ${ }^{23} \mathrm{Y}$ a la inversa, en el asunto Nicaragua, la corte, al evaluar el estatuto consuetudinario de la norma de no intervención, otorgó mucha importancia al hecho de que casi todos los países habían ratificado la Carta de las Naciones Unidas. ${ }^{24}$ Puede in-

tancia no lo habían hecho porque se creyeran obligados a hacerlo); ILA Report, cit., nota 13, principio 17 (iv) y comentario.

23 CIJ, North Sea..., cit., nota 7, p. 42, párr. 73.

24 CIJ, Case concerning..., cit., nota 12, pp. 99 y 100, párr. 188. Otro importante factor para que la corte tomara esta decisión fue que las resoluciones pertinentes de la Asamblea General de la ONU habían sido ampliamente aprobadas, en particular la Resolución 2625 (XXV) sobre las relaciones amistosas entre los Estados, que se aprobó sin votación. 
cluso darse el caso de que una disposición convencional refleje el derecho consuetudinario, aunque el tratado aún no esté en vigor, con tal de que haya una práctica similar suficiente, en particular de los Estados especialmente afectados, de manera que la probalilidad de que haya una oposición significativa a la norma en cuestión sea escasa. ${ }^{25}$

En la práctica, la redacción de normas convencionales contribuye a centrar la opinión jurídica mundial y tiene una influencia innegable en el ulterior comportamiento y en la convicción jurídica de los Estados. Esta realidad la reconoció la Corte Internacional de Justicia en el fallo de la causa Continental Shelf, en el que afirmó que "los convenios multilaterales pueden desempeñar un importante papel en la tarea de registrar y defininir las normas que se derivan de la costumbre, o de desarrollarlas de hecho". ${ }^{26}$ La corte reconoció, pues, que los tratados pueden codificar un derecho internacional consuetudinario preexistente, pero que también pueden sentar las bases para el desarrollo de nuevas costumbres fundadas en las normas contenidas en esos tratados. La corte llegó a afirmar incluso que "puede ocurrir que... una participación muy amplia y representativa en [un] convenio sea suficiente por sí misma, siempre que incluya a los Estados cuyos intereses estén especialmente afectados". ${ }^{27}$

En este estudio, se sigue el cauto proceder de tomar una amplia ratificación sólo como una indicación, que ha de evaluarse respecto de otros elementos de la práctica, en particular de la práctica de los Estados que no son parte en el tratado en cuestión. Una práctica concordante de los Estados que no son partes se ha considerado como una importante prueba positiva, mientras que una práctica contraria se ha estimado como una importante prueba negativa. Especialmente pertinente es asimismo la práctica de los Estados partes en relación con otros Estados que no son partes en el tratado.

25 CIJ, Continental Shelf..., cit., nota 6, p. 33, párr. 34 (La corte consideró que la noción de Zona Económica Exclusiva ya era parte del derecho internacional consuetudinario, aunque la Convención de las Naciones Unidas sobre el Derecho del Mar aún no había entrado en vigor, porque el número de reivindicaciones de una Zona Económica Exclusiva se había elevado a 56, incluidos algunos Estados especialmente afectados).

26 CIJ, Continental Shelf..., cit., nota 6, pp. 29 y 30, párr. 27.

27 CIJ, North Sea..., cit., nota 7, p. 42, párr. 73; véase también ILA Report, cit., nota 13, principios 20, 21, 24, 26 y 27, pp. 754-765. 
Así pues, este estudio no se ha circunscrito a la práctica de los Estados que no son partes en los tratados pertinentes de derecho internacional humanitario. Limitarlo a analizar únicamente la práctica de los treinta Estados y pico que no han ratificado los protocolos adicionales, por ejemplo, no cumpliría el requisito de que el derecho internacional consuetudinario se base en una práctica difundida y representativa. En la evaluación de la existencia de derecho internacional consuetudinario se ha tenido en cuenta, por tanto, el hecho de que, cuando se publicó el estudio, 162 Estados habían ratificado el Protocolo adicional I y 157 el Protocolo adicional II.

Cabe destacar que, en este estudio, no se ha intentado determinar la índole consuetudinaria de cada norma convencional de derecho internacional humanitario $\mathrm{y}$, en consecuencia, no se ha seguido necesariamente la estructura de los tratados existentes. Se ha procurado más bien examinar las cuestiones con el fin de establecer qué normas de derecho internacional consuetudinario pueden hallarse por inducción, basándose en la práctica de los Estados en relación con esos temas. Puesto que el proceder elegido no consistió en analizar cada disposición convencional con miras a establecer si es o no consuetudinaria, no puede concluirse que una determinada norma convencional no es consuetudinaria por el mero hecho de que no figura como tal en este estudio.

\section{ORGANIZACIÓN DEL ESTUDIO}

Para determinar la mejor manera de cumplir el encargo que le habían encomendado, el CICR consultó a un grupo de juristas expertos en derecho internacional humanitario, que formaron el Comité Directivo del estudio. ${ }^{28}$ Este comité aprobó un plan de acción en junio de 1996, y las investigaciones comenzaron en octubre de ese mismo año. Para llevarlas a cabo se utilizaron tanto fuentes nacionales como internacionales en las que estaba consignada la práctica de los Estados. El examen de esas fuentes se centró en las seis partes del estudio establecidas en el plan de acción:

28 El Comité Directivo estaba integrado por los profesores Georges Abi-Saab, Salah El-Din Amer, Ove Bring, Eric David, John Dugard, Florentino Feliciano, Horst Fischer, Françoise Hampson, Theodor Meron, Djamchid Momtaz, Milan Šahoviè y Raúl Emilio Vinuesa. 
- El principio de distinción

- Personas y bienes especialmente protegidos

- Métodos específicos de guerra

- Armas

- Trato debido a las personas civiles o fuera de combate

- Aplicación

\section{Investigación de las fuentes nacionales}

Puesto que las fuentes nacionales son más fácilmente accesibles en el correspondiente país, se decidió solicitar la cooperación de investigadores nacionales. Para ello se seleccionaron unos 50 países (nueve en África, 11 en América, 15 en Asia, uno en Oceanía y 11 en Europa) y, en cada uno de ellos, se encargó a un investigador o grupo de investigadores que elaborara un informe sobre la práctica del Estado respectivo. ${ }^{29}$ Estos países se escogieron en función de la representación geográfica, así como de recientes experiencias en diversos tipos de conflictos bélicos en los que se habían usado distintos métodos de guerra.

También se investigaron y recopilaron los manuales militares y la legislación nacional de los países no cubiertos por los informes sobre la práctica estatal. Facilitó esta tarea la red de delegaciones del CICR en todo el mundo y la amplia colección de leyes nacionales recopilada por el servicio de asesoramiento en derecho internacional humanitario de la institución.

\section{Investigación de las fuentes internacionales}

Los datos sobre la práctica de los Estados obtenidos de las fuentes internacionales los recopilaron seis equipos, cada uno de los cuales se concentró en una parte del estudio. ${ }^{30}$ Estos equipos indagaron la práctica

29 África: Angola, Argelia, Botsuana, Egipto, Etiopía, Nigeria, Ruanda, Sudáfrica y Zimbabue; América: Argentina, Brasil, Canadá, Chile, Colombia, Cuba, EUA, El Salvador, Nicaragua, Perú y Uruguay; Asia: China, India, Indonesia, Irak, Irán, Israel, Japón, Jordania, República de Corea, Filipinas, Kuwait, Líbano, Malasia, Pakistán y Siria; Oceanía: Australia; Europa: Alemania, Bélgica, Bosnia-Herzegovina, Croacia, España, Federación de Rusia, Francia, Italia, Países Bajos, Reino Unido y Yugoslavia.

30 El principio de distinción: profesor Georges Abi-Saab (relator) y Jean-François Quéguiner (investigador); Personas y bienes especialmente protegidos: profesor Horst 
de los Estados en el marco de las Naciones Unidas y de otras organizaciones internacionales, en particular la Unión Africana (antes Organización de la Unidad Africana), el Consejo de Europa, el Consejo de Cooperación del Golfo, la Unión Europea, la Liga de los Países Árabes, la Organización de los Estados Americanos, la Organización de la Conferencia Islámica y la Organización para la Seguridad y la Cooperación en Europa. También se recopiló derecho internacional jurisprudencial, en la medida en que prueba la existencia de normas de derecho internacional consuetudinario.

\section{Investigación en los archivos del CICR}

Para complementar las investigaciones de las fuentes nacionales e internacionales, el CICR examinó la documentación de sus propios archivos relacionada con los cerca de 40 conflictos armados recientes, 21 de los cuales se libraron en África, ocho en Asia, ocho en Europa y dos en América. ${ }^{31}$ Estos conflictos se escogieron, en general, de manera que ni ellos ni los países implicados ya hubieran sido antes objeto de un informe sobre la práctica de los Estados.

El resultado de este modo ternario de proceder - a saber, la investigación de las fuentes nacionales, internacionales y del CICR - es que se mencionan prácticas de todas las partes del mundo. Sin embargo, no se puede, naturalmente, pretender que esta investigación sea completa. Las investigaciones para este estudio se han centrado, ante todo, en la práctica de los últimos treinta años, con el fin de que el resultado sea un replan-

Fischer (relator), Gregor Schotten y Heike Spieker (investigadores); Métodos especificos de guerra: profesor Theodor Meron (relator) y Richard Desgagné (investigador); Armas: profesor Ove Bring (relator) y Gustaf Lind (investigador); Trato debido a las personas civiles o fuera de combate: Françoise Hampson (relatora) y Camille Giffard (investigadora); Aplicación: Eric David (relator) y Richard Desgagné (investigador).

31 Africa: Angola, Burundi, Chad, Chad-Libia, República Democrática del Congo, Eritrea-Yemen, Etiopía (1973-1994), Liberia, Mozambique, Namibia, Nigeria-Camerún, Ruanda, Sáhara Occidental; Senegal, Senegal-Mauritania, Sierra Leona, Somalia, Somalia-Etiopía, Sudán, Uganda y Yibuti, América: Guatemala y México; Asia: Afganistán, Camboya, India (Jammu y Cachemira), Papúa-Nueva Guinea, Sri Lanka, Tayikistán, Yemen y Yemen-Eritrea (también bajo África); Europa: Armenia-Azerbaiyán (Alto Karabaj), Chipre, ex Yugoslavia (conflicto en Yugoslavia 1991-1992), conflicto en Bosnia-Herzegovina (1992-1996), conflicto en Croacia (Krajinas) (1992-1995), Federación de Rusia (Chechenia), Georgia (Abjasia) y Turquía. 
teamiento del derecho internacional consuetudinario, aunque, cuando hacía al caso, también se citan fuentes más antiguas.

\section{Consultas a expertos}

En la primera tanda de consultas, el CICR invitó a los equipos internacionales de investigación a elaborar un "resumen analítico" con una evaluación preliminar del derecho internacional humanitario consuetudinario basada en las prácticas recopiladas. Estos resúmenes se debatieron en el Comité Directivo durante tres reuniones celebradas en Ginebra en 1998. En el marco de una segunda tanda de consultas, esos resúmenes analíticos se remitieron a un Grupo de Expertos Universitarios y Gubernamentales de todas las zonas del mundo, invitados por el CICR, a título personal, a dos reuniones con el Comité Directivo en Ginebra, en 1999. Durante esas reuniones, los expertos ayudaron a evaluar las prácticas recopiladas e indicaron las que consideraban que faltaban. ${ }^{32}$

\section{Redacción del informe}

La evaluación del Comité Directivo, revisada por el Grupo de Expertos Universitarios y Gubernamentales, sirvió de base para redactar el informe final. Los autores del estudio reexaminaron las prácticas, evaluaron de nuevo la existencia de una costumbre, revisaron la formulación y el orden de las normas y redactaron los comentarios. Se sometieron luego estos borradores al Comité Directivo, al Grupo de Expertos Universitarios y Gubernamentales y a la División Jurídica del CICR, para

32 Participaron, a título personal, en esta consulta los siguientes expertos universitarios y gubernamentales: Abdallah Ad-Douri (Irak), Paul Berman (Reino Unido), Sadi Çaycý (Turquía), Michael Cowling (Sudáfrica), Edward Cummings (EUA), Antonio de Icaza (México), Yoram Dinstein (Israel), Jean-Michel Favre (Francia), William Fenrick (Canadá), Dieter Fleck (Alemania), Juan Carlos Gómez Ramírez (Colombia), Jamshed A. Hamid (Pakistán), Arturo Hernández-Basave (México), Ibrahim Idriss (Etiopía), Hassan Kassem Jouni (Líbano), Kenneth Keith (Nueva Zelanda), Githu Muigai (Kenia), Rein Müllerson (Estonia), Bara Niang (Senegal), Mohamed Olwan (Jordania), Raul C. Pangalangan (Filipinas), Stelios Perrakis (Grecia), Paulo Sergio Pinheiro (Brasil), Arpád Prandler (Hungría), Pemmaraju Sreenivasa Rao (India), Camilo Reyes Rodríguez (Colombia), Itse E. Sagay (Nigeria), Harold Sandoval (Colombia), Somboon Sangianbut (Tailandia), Marat A. Sarsembayev (Kazajistán), Muhammad Aziz Shukri (Siria), Parlaungan Sihombing (Indonesia), Geoffrey James Skillen (Australia), Guoshun Sun (China), Bakhtyar Tuzmukhamedov (Rusia) y Karol Wolfke (Polonia). 
que los comentaran. El texto se actualizó nuevamente y se ultimó luego, teniendo en cuenta los comentarios recibidos.

\section{RESUMEN DE LOS RESULTADOS}

Se considera que la amplia mayoría de las disposiciones que figuran en los Convenios de Ginebra, incluido el artículo 3 común, forma parte del derecho internacional consuetudinario. ${ }^{33}$ Por otro lado, dado que actualmente 192 Estados son partes en los Convenios de Ginebra, éstos son vinculantes para casi todos los Estados como derecho convencional. Por consiguiente, el objeto propiamente dicho del estudio no era la índole consuetudinaria de las disposiciones de los convenios, sino más bien el examen de ciertas cuestiones reguladas por tratados que aún no han sido ratificados universalmente, en particular los protocolos adicionales, la Convención de La Haya para la Protección de los Bienes Culturales y algunas convenciones específicas que regulan el empleo de las armas.

En la descripción que se hace más adelante de las normas del derecho internacional consuetudinario no se trata de explicar por qué esas normas son consuetudinarias, ni tampoco de exponer la práctica en la que se basa esa conclusión. La explicación de por qué una norma se considera consuetudinaria se detalla en el volumen I del estudio, mientras que la práctica correspondiente se reseña en el volumen II.

\section{Conflictos armados internacionales}

El Protocolo adicional I codificó normas preexistentes del derecho internacional consuetudinario, pero también sentó las bases para la creación de nuevas normas consuetudinarias. La práctica recopilada en el estudio demuestra el profundo efecto que ha tenido el Protocolo adicional I en la práctica de los Estados, no sólo en conflictos armados internacionales, sino también en los no internacionales (véase más adelante). El estudio ha evidenciado, en particular, que los principios básicos del Protocolo adicional I han sido ampliamente aceptados, más ampliamente de lo que hace suponer el número de ratificaciones de ese instrumento.

33 CIJ, Legality of the Threat or Use..., cit., nota 8, pp. 257 y 258, párrs. 79 y 82 (a la luz de los Convenios de Ginebra) y Case concerning..., cit., nota 12, p. 114, párr. 218 (a la luz del artículo 3 común). 
Aunque el estudio no tenía por objeto determinar la índole consuetudinaria de algunas disposiciones convencionales en particular, se evidenció, a su término, que muchas normas consuetudinarias son idénticas o similares a las que figuran en el derecho convencional. Ejemplos de normas catalogadas como consuetudinarias que tienen disposiciones correspondientes en el Protocolo adicional I son: el principio de distinción entre civiles y combatientes y entre bienes de carácter civil y objetivos militares $; 34$ la prohibición de los ataques indiscriminados; ${ }^{35}$ el principio de proporcionalidad en el ataque; ${ }^{36}$ la obligación de tomar las precauciones que sean factibles en el ataque y contra los efectos de los ataques; ${ }^{37}$ la obligación de respetar y proteger al personal sanitario y religioso, las unidades y los medios de transporte sanitarios, ${ }^{38}$ al personal y los bienes de las organizaciones de ayuda humanitaria ${ }^{39}$ y a los periodistas civiles; ${ }^{40}$ la obligación de proteger a la misión médica; ${ }^{41}$ la prohibición de atacar localidades no defendidas y zonas desmilitarizadas; ${ }^{42}$ la obligación de dar cuartel y salvaguardar al enemigo fuera de combate; ${ }^{43}$ la prohibición de hacer padecer hambre;44 la prohibición de atacar los bienes indispensables para la supervivencia de la población civil ${ }^{45}$ la prohibición del uso inapropiado de los emblemas y de la perfidia; ${ }^{46}$ la obligación de respetar las garantías fundamentales de las personas civiles y fuera de combate; ${ }^{47}$ la obligación de buscar a las personas desaparecidas; ${ }^{48}$ y las protecciones específicas conferidas a las mujeres y los niños. ${ }^{49}$

34 Véase op. cit., nota 4, vol. I, normas 1 y 7.

35 Véase ibidem, normas 11-13.

36 Véase ibidem, norma 14.

37 Véase ibidem, normas 15-24.

38 Véase ibidem, normas 25 y 27-30.

39 Véase ibidem, normas 31 y 32.

40 Véase ibidem, norma 34.

41 Véase ibidem, norma 26.

42 Véase ibidem, normas 36 y 37.

43 Véase ibidem, normas 46-48.

44 Véase ibidem, norma 53.

45 Véase ibidem, norma 54.

46 Véase ibidem, normas 57-65.

47 Véase ibidem, normas 87-105.

48 Véase ibidem, norma 117.

49 Véase ibidem, normas 134-137. 


\section{Conflictos armados no internacionales}

En los últimos decenios, una parte considerable de la práctica ha insistido en la protección que brinda el derecho internacional humanitario en este tipo de conflictos. Esa práctica ha tenido una influencia significativa en la formación de derecho consuetudinario aplicable en los conflictos armados no internacionales. Al igual que el Protocolo adicional I, el Protocolo adicional II ha tenido amplias repercusiones en esta práctica y, en consecuencia, muchas de sus disposiciones se consideran ahora como parte del derecho internacional consuetudinario. Ejemplos de normas que se consideran consuetudinarias y que tienen disposiciones correspondientes en el Protocolo adicional II son: la prohibición de los ataques contra la población civil; ${ }^{50}$ la obligación de respetar y proteger al personal sanitario y religioso, las unidades y los medios de transporte sanitarios; ${ }^{51}$ la obligación de proteger a la misión médica; ${ }^{52}$ la prohibición de hacer padecer hambre; 53 la prohibición de los ataques contra los bienes indispensables para la supervivencia de la población civil ${ }^{54}$ la obligación de respetar las garantías fundamentales de las personas civiles y fuera de combate; 55 la obligación de buscar, respetar y proteger a los heridos, los enfermos y los náufragos; 56 la obligación de buscar y proteger a las personas fallecidas; ${ }^{57}$ la obligación de proteger a las personas privadas de libertad; ${ }^{58}$ la prohibición de los desplazamientos forzados de la población civil;59 y las protecciones específicas conferidas a las mujeres y los niños. ${ }^{60}$

Sin embargo, la contribución más significativa del derecho internacional consuetudinario a la regulación de los conflictos armados internos es que va más allá de las disposiciones del Protocolo adicional II. En efecto, la práctica ha creado un número considerable de normas consue-

50 Véase ibidem, norma 1.

51 Véase ibidem, normas 25 y 27-30.

52 Véase ibidem, norma 26.

53 Véase ibidem, norma 53.

54 Véase ibidem, norma 54.

55 Véase ibidem, normas 87-105.

56 Véase ibidem, normas 109-111.

57 Véase ibidem, normas 112 y 113.

58 Véase ibidem, normas 118, 119, 121 y 125.

59 Véase ibidem, norma 129.

60 Véase ibidem, normas 134-137. 
tudinarias que son más detalladas que las a menudo rudimentarias disposiciones del Protocolo adicional II y, por consiguiente, ha llenado importantes lagunas en la regulación de los conflictos internos.

Por ejemplo, el Protocolo adicional II sólo regula de manera rudimentaria la conducción de las hostilidades. El artículo 13 dispone que "[n]o serán objeto de ataque la población civil como tal, ni las personas civiles... salvo si participan directamente en las hostilidades y mientras dure tal participación". A diferencia del Protocolo adicional I, el Protocolo adicional II no contiene normas y definiciones específicas sobre los principios de distinción y de proporcionalidad.

Sin embargo, las lagunas en la regulación de la conducción de las hostilidades que establece el Protocolo adicional II las ha colmado, en gran medida, la práctica de los Estados, que ha dado lugar a la creación de normas paralelas a las del Protocolo adicional I pero que son aplicables, como derecho consuetudinario, a los conflictos armados no internacionales. Esta preceptiva abarca los principios fundamentales referentes a la conducción de las hostilidades e incluye normas sobre personas y bienes expresamente protegidos y métodos bélicos específicos. ${ }^{61}$

Análogamente, el Protocolo adicional II sólo contiene una disposición muy general sobre la ayuda humanitaria a la población civil necesitada. En el artículo 18 (2), se estipula que "[c]uando la población civil esté padeciendo privaciones extremadas por la falta de abastecimientos indispensables para su supervivencia... se emprenderán... acciones de socorro en favor de la población civil, de carácter exclusivamente humanitario e imparcial y realizadas sin distinción alguna de carácter desfavorable". A diferencia del Protocolo adicional I, el Protocolo adicional II no contiene disposiciones específicas que exijan que se respete y proteja al personal y los bienes de las organizaciones que prestan ayuda humanitaria, que obliguen a las partes en conflicto a permitir y facilitar el paso rápido y sin trabas del socorro humanitario en favor de la población civil necesitada y que garanticen la libertad de movimiento del personal hu-

61 Véase, por ejemplo, ibidem, normas 7-10 (distinción entre bienes de carácter civil y objetivos militares), normas 11-13 (ataques indiscriminados), norma 14 (proporcionalidad en el ataque), normas 15-21 (precauciones en el ataque), normas 22-24 (precauciones contra los efectos de los ataques), normas 31 y 32 (personal y bienes de organizaciones de ayuda humanitaria), norma 34 (periodistas civiles), normas 35-37 (zonas protegidas), normas 46-48 (no dar cuartel), normas 55 y 56 (acceso de la ayuda humanitaria) y normas 57-65 (engaño). 
manitario autorizado, aunque puede argüirse que tales exigencias están implícitas en el artículo 18 (2) del protocolo. Estos requisitos han cristalizado, de todos modos, en el derecho internacional consuetudinario aplicable tanto a los conflictos armados internacionales como a los no internacionales como resultado de una práctica extensa, representativa y poco menos que uniforme al respecto.

En este sentido, cabe señalar que mientras los protocolos adicionales I y II exigen el consentimiento de las partes en conflicto para que se lleven a cabo las acciones de socorro, ${ }^{62}$ en la mayor parte de la práctica recopilada no se menciona este requisito. De todos modos, es evidente que una organización humanitaria no puede actuar sin el consentimiento de las partes concernidas, el cual, por otro lado, no puede denegarse arbitrariamente. Si se sabe que se está haciendo padecer hambre a una población civil y que una organización humanitaria que presta socorro de manera imparcial y no discriminatoria puede remediar esa situación, las partes están obligadas a dar su consentimiento. ${ }^{63} \mathrm{Si}$ bien es cierto que el consentimiento no puede denegarse por razones arbitrarias, la práctica reconoce que la parte concernida puede controlar la acción de socorro y que el personal humanitario debe respetar la legislación nacional en vigor sobre el acceso al territorio y los requisitos de seguridad.

\section{Cuestiones que deben aclararse}

El estudio también reveló numerosos ámbitos en que la práctica aún no está clara. Por ejemplo, si bien los términos "combatientes" y "personas civiles" están claramente definidos en los conflictos armados internacionales, ${ }^{64}$ en los conflictos no internacionales la práctica es ambigua en lo que respecta a si, para los efectos de la conducción de las hostilidades,

62 Véase Protocolo adicional I, artículo 70 (1) y Protocolo adicional II, artículo 18 (2).

63 Véase Junod, Sylvie-Stoyanka et al., Comentario del Protocolo del 8 de junio de 1977 adicional a los Convenios de Ginebra del 12 de agosto de 1949 relativo a la protección de las víctimas de los conflictos armados sin carácter internacional (Protocolo II), Santa Fe de Bogotá, CICR-Plaza \& Janés Editores, 1998, párr. 4885; véase también párr. 2805 en id., Comentario del Protocolo del 8 de junio de 1977 adicional a los Convenios de Ginebra del 12 de agosto de 1949 relativo a la protección de las víctimas de los conflictos armados internacionales (Protocolo I), Santa Fe de Bogotá, CICR-Plaza \& Janés Editores, 2001.

64 Véase op. cit., nota 4, vol. I, norma 3 (combatientes), norma 4 (fuerzas armadas) y norma 5 (personas civiles y población civil). 
los miembros de los grupos armados de oposición se consideran miembros de las fuerzas armadas o personas civiles. En particular, no está claro si los miembros de grupos armados de oposición son civiles que pierden su protección contra los ataques cuando participan directamente en las hostilidades o si pueden ser atacados como tales. Esta falta de claridad también se halla en el derecho convencional. El Protocolo adicional II, por ejemplo, no contiene una definición de personas civiles o de población civil, aunque estos términos se utilizan en varias disposiciones. ${ }^{65}$ En tratados posteriores, aplicables en conflictos armados no internacionales, también se emplean los términos de "personas civiles" y "población civil" sin definirlos. ${ }^{66}$

Otro aspecto de incertidumbre que afecta la regulación de los conflictos armados, tanto internacionales como no internacionales, es la ausencia de una definición precisa de la expresión "participación directa en las hostilidades". Es indiscutible que la protección contra los ataques se pierde cuando una persona civil emplea armas y otros medios para cometer actos de violencia contra las fuerzas humanas o materiales del enemigo. Pero también existe una práctica considerable que da escasa o ninguna orientación sobre la interpretación de la expresión "participación directa", al establecer, por ejemplo, que debe hacerse una evaluación caso por caso, o al repetir simplemente la norma general de que la participación directa en las hostilidades hace que las personas civiles pierdan la protección contra los ataques. Una cuestión asociada a ésta es la de cómo calificar a una persona en caso de duda. Habida cuenta de estas incertidumbres, el CICR está procurando aclarar la noción de participación directa por medio de una serie de reuniones de expertos, que comenzaron en $2003 .{ }^{67}$

Otra cuestión aún pendiente es el alcance exacto y el ámbito de aplicación del principio de proporcionalidad en el ataque. A pesar de que el estudio demostró que este principio cuenta con un respaldo generalizado,

65 Protocolo adicional II, artículos $13-15$ y 17 y 18.

66 Véase, por ejemplo, el Protocolo II enmendado de la Convención sobre Ciertas Armas Convencionales, artículos 3 (7)-(11); Protocolo III de la Convención sobre Ciertas Armas Convencionales, artículo 2; Convención de Ottawa sobre la Prohibición de las Minas Antipersonal, Preámbulo; Estatuto de la CPI, artículo 8 (2) (e), (iii) y (viii).

67 Véase, por ejemplo, Participación Directa en las Hostilidades con Arreglo al Derecho Internacional Humanitario, informe preparado por el CICR, Ginebra, septiembre de 2003, disponible en www.cicr.org/spa. 
no aclara más que lo hace el derecho convencional acerca de cómo hacer compatible la ventaja militar y las pérdidas civiles incidentales.

\section{Cuestiones seleccionadas sobre la conducción de las hostilidades}

Los protocolos adicionales I y II introdujeron una nueva norma de prohibición de los ataques contra las obras y las instalaciones que contienen fuerzas peligrosas, aunque sean objetivos militares, cuando tales ataques puedan producir la liberación de dichas fuerzas y causar, en consecuencia, pérdidas importantes entre la población civil. ${ }^{68} \mathrm{~A}$ pesar de que no queda claro si esas normas específicas forman parte del derecho consuetudinario, la práctica muestra que los Estados son conscientes del alto riesgo de los graves estragos incidentales que pueden causar los ataques contra esas obras e instalaciones cuando son objetivos militares. Por consiguiente, reconocen que, en cualquier conflicto armado, se ha de poner mucho cuidado, en caso de ataque, para evitar la liberación de fuerzas peligrosas y causar, en consecuencia, pérdidas importantes entre la población civil. El estudio llega a la conclusión de que este requisito forma parte del derecho internacional consuetudinario aplicable en cualquier conflicto armado.

Otra norma introducida en el Protocolo adicional I es la prohibición de emplear medios y métodos bélicos que hayan sido concebidos para causar, o de los que quepa prever que causen, daños extensos, duraderos y graves al medio ambiente natural. Desde la adopción del Protocolo adicional I, esta prohibición ha recibido tanto apoyo en la práctica de los Estados que ha cristalizado en derecho consuetudinario, aunque algunos Estados han sostenido, con insistencia, que la norma no se aplica a las armas nucleares y que, por ende, puede no ser vinculante por lo que respecta a las armas nucleares. ${ }^{69}$ Más allá de esta norma específica, el estudio halló que el medio ambiente natural se considera un bien civil y, como tal, está protegido por los mismos principios y normas que protegen a otros bienes de carácter civil, en particular por los principios de distinción y proporcionalidad y por el requisito de tomar precauciones en el ataque. Esto significa que ningún elemento del medio ambiente natural puede ser ob-

68 Protocolo adicional I, artículo 56 (1) (seguido, sin embargo, por excepciones en el apdo. (2)) y Protocolo adicional II, artículo 15 (sin excepciones).

69 Véase op. cit., nota 4, vol. I, norma 45. 
jeto de ataque, a menos que sea un objetivo militar, y que están prohibidos los ataques contra un objetivo militar de los que se pueda prever que causen daños incidentales al medio ambiente que sean excesivos en relación con la ventaja militar directa prevista. En su opinión consultiva sobre el Nuclear Weapons case, por ejemplo, la Corte Internacional de Justicia afirmó que "los Estados deben tomar en consideración las cuestiones ambientales cuando evalúen qué es necesario y proporcional en la búsqueda de objetivos militares legítimos. ${ }^{70}$ Además, se exige que las partes en conflicto tomen todas las precauciones que sean factibles en la conducción de las hostilidades con el fin de evitar o reducir a un mínimo los daños incidentales al medio ambiente. La falta de certeza científica acerca de los efectos que puedan tener en el medio ambiente algunas operaciones militares no exime a una parte en conflicto de tomar esas precauciones. $^{71}$

Hay asimismo otras cuestiones que no están tratadas debidamente en los protocolos adicionales. Por ejemplo, los protocolos adicionales no contienen disposición específica alguna sobre la protección del personal y los bienes empleados en las misiones de mantenimiento de la paz. Sin embargo, en la práctica, ese personal y esos bienes han recibido la misma protección contra los ataques que las personas civiles y los bienes de carácter civil, respectivamente. En consecuencia, se ha incluido en la práctica de los Estados y en el Estatuto de la Corte Penal Internacional una norma que prohíbe los ataques contra el personal y los bienes de las misiones de mantenimiento de la paz de conformidad con la Carta de las Naciones Unidas, siempre que tengan derecho a recibir la protección que el derecho internacional humanitario confiere a las personas civiles y los bienes de carácter civil. Esa norma forma ahora parte del derecho internacional consuetudinario aplicable en cualquier tipo de conflicto armado. ${ }^{72}$

Numerosas cuestiones relacionadas con la conducción de las hostilidades están reguladas por el Reglamento de La Haya. Si desde hace mucho tiempo se considera este reglamento como consuetudinario en los conflictos armados internacionales, ${ }^{73}$ ahora también se aceptan algunas

70 CIJ, Legality of the Threat or Use..., cit., nota 8, párr. 30.

71 Véase $o p$. cit., nota 4, vol. I, norma 44.

72 Véase ibidem, norma 33.

73 Tribunal Militar Internacional de Nuremberg, Case of the Major War Criminals, fallo, 1o. de octubre de 1946, Official Documents, vol. I, pp. 253 y 254. 
de sus normas como consuetudinarias en los conflictos armados no internacionales. Por ejemplo, las antiguas normas de derecho internacional consuetudinario que prohíben: 1) La destrucción o la apropiación de los bienes del enemigo, a menos que lo exija la necesidad militar, así como 2) El pillaje, se aplican también a los conflictos armados no internacionales. Se entiende por pillaje la apropiación forzosa de bienes privados del enemigo para un uso personal o privado. ${ }^{74}$ Ninguna de estas dos prohibiciones afecta a la práctica consuetudinaria de adueñarse, como botín de guerra, del material militar perteneciente al adversario.

Según el derecho internacional consuetudinario, los jefes militares pueden entrar en tratos no hostiles valiéndose de cualquier medio de comunicación, pero ese contacto debe basarse en la buena fe. La práctica indica que la comunicación puede realizarse por intermediarios conocidos como parlamentarios, pero también por otros medios, como el teléfono o la radio. Un parlamentario es una persona perteneciente a una parte en conflicto que ha sido autorizada a entablar conversaciones con otra parte en conflicto y que goza, por ello, de inviolabilidad. Se ha concluido que sigue siendo válido el método tradicional para que un parlamentario se dé a conocer como tal, a saber, avanzar enarbolando una bandera blanca. Además, otra práctica reconocida es que las partes recurran a una tercera parte para que facilite la comunicación, por ejemplo, una potencia protectora o una organización humanitaria imparcial y neutral que actúe como sustituto, en particular el CICR, pero también una organización internacional o una fuerza de mantenimiento de la paz. La práctica recopilada muestra que varias instituciones y organizaciones han actuado como intermediarios de negociaciones en conflictos armados internacionales y no internacionales, y que esa mediación es generalmente aceptada. Las normas que rigen el papel de los parlamentarios se remontan al Reglamento de La Haya y están consideradas desde hace mucho tiempo como consuetudinarias en los conflictos armados internacionales. Habida cuenta de la práctica de los últimos cincuenta años aproximadamente, se han convertido en consuetudinarias también en los conflictos armados no internacionales. ${ }^{75}$

74 Véase Elementos de los crímenes, Corte Penal Internacional, Crímenes de guerra: saquear (artículo 8 (2) (b) (xvi) y (e) (v) del Estatuto de la CPI).

75 Véase op. cit., nota 4, vol. I, normas 67-69. 
La práctica pone de manifiesto dos corrientes en el derecho que protege los bienes culturales. Una primera corriente se remonta al Reglamento de La Haya y exige que, en las operaciones militares, se ponga especial cuidado en evitar dañar los edificios dedicados al culto religioso, las artes, las ciencias, la educación o la beneficencia, así como los monumentos históricos, siempre que no sean objetivos militares. También prohíbe destruir, tomar o dañar intencionadamente esos edificios y monumentos. Estas normas, que se consideraban consuetudinarias en conflictos armados internacionales desde hacía mucho tiempo, también se aceptan ahora como tales en los conflictos armados no internacionales.

Una segunda corriente se basa en las disposiciones específicas de la Convención de La Haya de 1954 para la protección de los bienes culturales, que protege el patrimonio cultural que "presenta una gran importancia para todos los pueblos del mundo" e introduce el empleo de un signo distintivo específico para identificar esos bienes. El derecho consuetudinario exige hoy que no se ataque ni se utilicen esos bienes para fines que puedan exponerlos a la destrucción o el deterioro, a no ser que lo exija imperativamente la necesidad militar. Prohíbe asimismo toda forma de robo, pillaje o apropiación indebida de esos bienes, así como cualquier acto de vandalismo en su contra. Estas prohibiciones, que corresponden a disposiciones establecidas en la Convención de La Haya, demuestran la influencia que la convención ha tenido en la práctica de los Estados relativa a la protección de bienes culturales importantes.

\section{Armas}

Se llegó a la conclusión, en el estudio, de que los principios generales por los que se prohíbe el empleo de armas que causan males superfluos o sufrimientos innecesarios, así como de armas de efectos indiscriminados, son consuetudinarios en todo conflicto armado. Además, y basándose principalmente en estos principios, la práctica de los Estados ha prohibido el empleo (o ciertos tipos de empleos), en virtud del derecho internacional consuetudinario, de diversas armas específicas, a saber: las toxinas o armas tóxicas; las armas biológicas; las armas químicas, las sustancias anti-disturbios como método de guerra; los herbicidas como método de guerra; ${ }^{76}$ las balas que se ensanchan o se aplastan fácilmente 
en el cuerpo humano; las balas que explotan en el cuerpo humano; las balas cuyo efecto principal sea lesionar mediante fragmentos no localizables por rayos $\mathrm{X}$ en el cuerpo humano; las armas trampa vinculadas o asociadas de algún modo a objetos o personas especialmente protegidos por el derecho internacional humanitario o que pueden atraer a las personas civiles; y las armas láser específicamente concebidas, como única o una más de sus funciones de combate, para causar ceguera permanente a la vista no amplificada.

Algunas armas que no están prohibidas como tales por el derecho consuetudinario están, de todos modos, sujetas a restricciones, como son las minas antipersonal y las armas incendiarias.

Deben realizarse especiales esfuerzos para reducir al mínimo los efectos indiscriminados de las minas antipersonal. Esto incluye, por ejemplo, el principio de que una parte en conflicto que emplea minas antipersonal debe registrar su ubicación, en la medida de lo posible. Además, cuando cesen las hostilidades activas, una parte en conflicto que haya empleado minas antipersonal debe retirarlas, hacerlas inofensivas para la población civil o facilitar su remoción.

Dado que la Convención de Ottawa ha sido ratificada por 140 Estados, y otros están en camino de hacerlo, la mayor parte de los Estados se ha obligado por ese instrumento a no emplear, producir, almacenar ni transferir minas antipersonal. A pesar de que esta prohibición no forma actualmente parte del derecho internacional consuetudinario debido a una práctica contraria significativa de Estados que no son partes en la convención, casi todos los Estados, incluidos los que no son partes en la Convención de Ottawa y no están en favor de la prohibición inmediata de las minas terrestres, han reconocido la necesidad de esforzarse por la plena eliminación de esas armas.

El empleo antipersonal de armas incendiarias está prohibido, salvo si no es factible emplear un arma menos dañina para poner a una persona fuera de combate. Por otra parte, si se emplean, hay que procurar evitar,

químicas; la prohibición de los ataques contra la vegetación que no sea un objetivo militar; la prohibición de los ataques que podrían causar la muerte incidental de personas civiles, lesiones a personas civiles y daños a bienes de carácter civil, o una combinación de estos, cuando sea de prever que serían excesivos en relación con la ventaja militar concreta y directa prevista; y la prohibición de causar daños extensos, duraderos y graves al medio ambiente natural. Véase ibidem, norma 76. 
o reducir en todo caso al mínimo, la muerte incidental de personas civiles, las lesiones a personas civiles y los daños a bienes de carácter civil.

La mayor parte de estas normas corresponden a disposiciones convencionales que sólo son aplicables, en principio, en conflictos armados internacionales. Esa tendencia se ha invertido paulatinamente gracias, por ejemplo, a la enmienda aprobada en 1996 del Protocolo II de la Convención sobre Ciertas Armas Convencionales, que también se aplica ahora a los conflictos armados no internacionales y, más recientemente, a la enmienda aprobada en 2001 de la Convención sobre Ciertas Armas Convencionales, con el fin de ampliar el ámbito de aplicación de los protocolos I-IV a los conflictos armados no internacionales. Las prohibiciones y restricciones consuetudinarias antes mencionadas se aplican, pues, en todo conflicto armado.

Cuando se encomendó al CICR realizar el estudio sobre el derecho internacional humanitario consuetudinario, la Corte Internacional de Justicia estaba examinando la licitud de la amenaza o del empleo de armas nucleares, en respuesta a una solicitud de una opinión consultiva al respecto que le había dirigido la Asamblea General de la ONU. El CICR decidió entonces no efectuar su propio análisis de esta cuestión. En su opinión consultiva, la Corte Internacional de Justicia sostuvo unánimemente que "una amenaza o el empleo de armas nucleares también debería ser compatible con las exigencias del derecho internacional aplicable en los conflictos armados, particularmente las de los principios y las normas del derecho internacional humanitario". ${ }^{77}$ Esta decisión es significativa, puesto que varios Estados iniciaron la negociación del Protocolo adicional I a condición de que en el protocolo no se aplicara al empleo de armas nucleares. La opinión de la corte, sin embargo, significa que las normas sobre la conducción de las hostilidades y los principios generales sobre el uso de las armas se aplican al empleo de armas nucleares. En virtud de esos principios y normas, la corte concluyó que "la amenaza o el uso de armas nucleares sería, en general, contrario a las normas del derecho internacional aplicable en los conflictos armados y, en particular, a los principios y las normas del derecho humanitario". ${ }^{78}$

77 CIJ, Legality of the Threat or Use..., cit., nota 8, p. 226.

78 Idem; véase también Asamblea General de la ONU, quincuagésimo primer periodo de sesiones, Primera Comisión, Declaración del Comité Internacional de la Cruz Roja, UN Doc. A/C. 1/51/PV.8, 18 de octubre de 1996, p. 10, reproducida en RICR, núm. 


\section{Garantías fundamentales}

Las garantías fundamentales se aplican a todos los civiles en poder de una parte en conflicto que no participan o han dejado de participar activamente en las hostilidades, así como a todas las personas fuera de combate. Dado que las garantías fundamentales son normas primordiales que se aplican a todas las personas, en el estudio no se subdividieron en normas específicas según diferentes categorías de personas.

Todas estas garantías fundamentales tienen una base sólida en el derecho internacional humanitario aplicable tanto en los conflictos armados internacionales como en los no internacionales. En el estudio, la mayor parte de las normas relativas a las garantías fundamentales están redactadas en el lenguaje del derecho humanitario tradicional, porque éste expresa mejor la sustancia de la norma consuetudinaria correspondiente. ${ }^{79}$ Sin embargo, algunas normas se han enunciado de modo que plasmen la esencia de una serie de disposiciones detalladas relativas a un tema determinado, en particular las normas que prohíben los trabajos forzosos abusivos y no remunerados, las desapariciones forzosas y las detenciones arbitrarias, así como la norma que exige que se respete la vida familiar. ${ }^{80}$

Cuando se estimó pertinente, se incluyó en el estudio la práctica concerniente al derecho internacional de los derechos humanos, particularmente en el capítulo sobre las garantías fundamentales. Esto se hizo porque el derecho internacional de los derechos humanos continúa aplicándose durante los conflictos armados, como se declara expresamente

139, pp. 125 y 126, disponible en www.cicr.org/spa ("es difícil para el CICR plantearse cómo un empleo de armas nucleares podría avenirse con las normas del derecho internacional humanitario").

79 Esas normas incluyen las garantías fundamentales de que las personas civiles y las personas fuera de combate sean tratadas con humanidad y sin distinción de índole desfavorable; la prohibición del homicidio; la prohibición de la tortura, los tratos crueles e inhumanos y los atentados contra la dignidad personal, en particular los tratos humillantes y degradantes; la prohibición de los castigos corporales; la prohibición de las mutilaciones, de los experimentos médicos o científicos; la prohibición de los abusos sexuales y de otras formas de violencia sexual; la prohibición de la esclavitud y la trata de esclavos en todas sus formas; la prohibición de la toma de rehenes; la prohibición del empleo de escudos humanos; las garantías de un proceso equitativo; la prohibición de los castigos colectivos; y el requisito de que se respeten las convicciones y las prácticas religiosas de las personas fuera de combate. Véase, op. cit., nota 4, vol. I, normas 87-94, 96 y 97 y $100-104$.

80 Véase ibidem, normas 95, 98, 99 y 105. 
en los propios tratados de derechos humanos, aunque algunas disposiciones puedan suspenderse, bajo ciertas condiciones, en caso de emergencia pública. La aplicabilidad ininterrumpida del derecho de los derechos humanos durante los conflictos armados la han confirmado, en numerosas ocasiones, tanto la práctica de los Estados como los organismos de defensa de los derechos humanos y la Corte Internacional de Justicia. ${ }^{81} \mathrm{Re}$ cientemente, la corte, en su opinión consultiva sobre las consecuencias jurídicas de la construcción de un muro en los territorios palestinos ocupados, confirmó que "la protección que ofrecen los convenios y convenciones de derechos humanos no cesa en caso de conflicto armado" y que, si bien "algunos derechos pueden estar contemplados exclusivamente en el derecho internacional humanitario, otros pueden estar contemplados exclusivamente en el derecho de los derechos humanos y otros pueden estar contemplados en ambas ramas del derecho internacional". ${ }^{82}$ A pesar de que en el estudio no se propone hacer una evaluación del derecho consuetudinario de los derechos humanos, se incluyó la práctica con arreglo al derecho de los derechos humanos con el fin de respaldar, reforzar y aclarar principios análogos del derecho internacional humanitario.

\section{Aplicación}

Numerosas normas sobre la aplicación del derecho internacional humanitario forman ahora parte del derecho internacional consuetudinario. En particular, cada parte en conflicto debe respetar y hacer respetar el derecho internacional humanitario por sus fuerzas armadas y otras personas o grupos que actúen de hecho bajo sus instrucciones, su dirección o su control. Por consiguiente, todas las partes en conflicto, incluidos los grupos armados de oposición, deben instruir a sus fuerzas armadas en derecho internacional humanitario. Más allá de estas obligaciones generales, no queda tan claro en qué medida otros mecanismos de aplicación específicos que son obligatorios para los Estados vinculan también a los grupos armados de oposición. Por ejemplo, la obligación de dar órdenes e instrucciones a las fuerzas armadas para que velen por el respeto del derecho internacional humanitario está claramente establecida en el dere-

81 Véase ibidem, Introducción al capítulo 32, Garantías fundamentales.

82 CIJ, Consecuencias Jurídicas de la Construcción de un Muro en el Territorio Palestino Ocupado, opinión consultiva, 9 de julio de 2004, párr. 106 (disponible en www.icj-cij.org). 
cho internacional para los Estados, pero no para los grupos armados de oposición. Análogamente, los Estados están obligados a poner a disposición, si es necesario, asesores jurídicos para que aconsejen a los jefes militares, en el nivel adecuado, sobre la aplicación del derecho internacional humanitario, obligación que no existe para los grupos armados de oposición.

Además, un Estado es responsable de las violaciones del derecho internacional humanitario que le sean imputables y debe reparar cabalmente las pérdidas o las lesiones causadas por tales violaciones. No se ha establecido con claridad si los grupos armados de oposición tienen una responsabilidad equivalente por violaciones cometidas por sus miembros y cuáles serían las consecuencias de esa responsabilidad. Teniendo en cuenta que, como se ha señalado antes, los grupos armados de oposición deben respetar el derecho internacional humanitario y actuar bajo las órdenes de un "mando responsable", ${ }^{83}$ podría aducirse que esos grupos son responsables de los actos cometidos por sus miembros. No obstante, las consecuencias de esta responsabilidad no están claras, en particular, no se ha establecido en qué medida tienen la obligación de reparar plenamente las pérdidas o lesiones causadas, aunque en muchos países las víctimas pueden entablar un proceso civil por daños contra los infractores.

Por lo que respecta a la responsabilidad civil, el derecho internacional humanitario consuetudinario atribuye una responsabilidad penal a todas las personas que cometen $u$ ordenan cometer un crimen de guerra, o que son de alguna otra manera responsables, como jefes o superiores, de la comisión de crímenes de guerra. La aplicación de la normativa referente a los crímenes de guerra, es decir, la investigación de los crímenes de guerra y el enjuiciamiento de los presuntos responsables, es una obligación que incumbe a los Estados. Los Estados pueden cumplir esta obligación instaurando un tribunal internacional o tribunales mixtos para tales fines.

\section{CONCLUSIÓN}

La finalidad del estudio no era determinar la índole consuetudinaria de cada norma convencional del derecho internacional humanitario, sino intentar analizar diversas cuestiones con el fin de determinar qué normas 
de derecho internacional consuetudinario pueden hallarse por inducción basándose en la práctica de los Estados relacionada con esas cuestiones. No obstante, un breve examen de algunos de los resultados del estudio muestra que los principios y las normas contenidos en el derecho convencional han tenido amplia aceptación en la práctica y han influido en gran medida en la formación del derecho internacional consuetudinario. Muchos de esos principios y normas forman parte ahora del derecho internacional consuetudinario y son, por ello, vinculantes para todos los Estados, independientemente de los tratados que hayan ratificado, así como para los grupos armados de oposición en el caso de las normas aplicables a todas las partes en un conflicto no internacional.

El estudio pone asimismo de manifiesto que numerosas normas del derecho internacional consuetudinario son aplicables tanto en conflictos armados internacionales como en los no internacionales, y muestra en qué medida la práctica de los Estados ha ido más allá del derecho convencional existente y ha ampliado las normas aplicables en los conflictos armados no internacionales. Así pues, la regulación de la conducción de las hostilidades y el trato debido a las personas en los conflictos armados internos es más detallada y completa que la que brinda el derecho convencional. Aún queda por aclarar hasta qué punto, desde un punto de vista humanitario y militar, esta regulación más detallada y completa es suficiente y si son necesarios nuevos desarrollos del derecho.

Al igual que para el derecho convencional, la aplicación efectiva de las normas de derecho internacional consuetudinario requiere una labor de difusión y formación, así como la adopción de medidas de ejecución. Esas normas deberían incorporarse en los manuales militares y la legislación nacional, si aún no figuran en éstos.

El estudio pone también al descubierto ámbitos en los que el derecho no es claro, así como cuestiones que requieren mayor clarificación o acuerdo, como la definición de personas civiles en los conflictos armados no internacionales, el concepto de participación directa en las hostilidades, y el alcance y la aplicación del principio de proporcionalidad.

A la luz de los logros alcanzados hasta la fecha y del trabajo que aún queda por hacer, el estudio no debería considerase como el punto final, sino como el comienzo de un nuevo proceso destinado a mejorar la comprensión y el acuerdo sobre los principios y las normas del derecho internacional humanitario. En ese proceso, el estudio puede servir de base de 
un debate y un diálogo enriquecedores sobre la aplicación, la clarificación y el posible desarrollo del derecho.

\author{
VII. ANEXO \\ LISTA DE LAS NORMAS CONSUETUDINARIAS DEL DERECHO \\ INTERNACIONAL HUMANITARIO* \\ EL PRINCIPIO DE DISTINCIÓN \\ Distinción entre civiles y combatientes
}

Norma 1. Las partes en conflicto deberán distinguir en todo momento entre personas civiles y combatientes. Los ataques sólo podrán dirigirse contra combatientes. Los civiles no deben ser atacados [CAI/CANI].

Norma 2. Quedan prohibidos los actos o las amenazas de violencia cuya finalidad principal sea aterrorizar a la población civil [CAI/CANI].

Norma 3. Todos los miembros de las fuerzas armadas de una parte en conflicto son combatientes, excepto el personal sanitario y religioso [CAI].

Norma 4. Las fuerzas armadas de una parte en conflicto se componen de todas las fuerzas, agrupaciones y unidades armadas y organizadas que estén bajo un mando responsable de la conducta de sus subordinados ante esa parte [CAI].

Norma 5. Son personas civiles quienes no son miembros de las fuerzas armadas. La población civil comprende a todas las personas civiles [CAI/CANI].

Norma 6. Las personas civiles gozan de protección contra los ataques, salvo si participan directamente en las hostilidades y mientras dure tal participación [CAI/CANI].

* La siguiente lista se basa en las conclusiones expuestas en el volumen I del estudio sobre el derecho internacional humanitario consuetudinario. Dado que este estudio no tenía por objeto determinar la índole consuetudinaria de cada norma contenida en los tratados de derecho internacional humanitario, la lista no sigue necesariamente la estructura de los tratados existentes. El ámbito de aplicación de las normas se indica entre corchetes: las siglas CAI indican las normas consuetudinarias aplicables en los conflictos armados internacionales y CANI las que se aplican en los conflictos armados no internacionales. En este último caso, algunas normas llevan la indicación de "c.a. en CANI" (cabe aplicarla en CANI), porque la práctica ha seguido en general esa dirección, aunque esté menos extendida. 


\section{Distinción entre bienes de carácter civil y objetivos militares}

Norma 7. Las partes en conflicto deberán hacer en todo momento la distinción entre bienes de carácter civil y objetivos militares. Los ataques sólo podrán dirigirse contra objetivos militares. Los bienes de carácter civil no deben ser atacados [CAI/CANI].

Norma 8. Por lo que respecta a los bienes, los objetivos militares se limitan a aquellos bienes que por su naturaleza, ubicación, finalidad o utilización contribuyan eficazmente a la acción militar y cuya destrucción total o parcial, captura o neutralización ofrezca, en las circunstancias del caso, una ventaja militar definida $[\mathrm{CAI} / \mathrm{CANI}]$.

Norma 9. Son bienes de carácter civil todos los bienes que no son objetivos militares [CAI/CANI].

Norma 10. Los bienes de carácter civil gozan de protección contra los ataques, salvo si son objetivos militares y mientras lo sean [CAI/CANI].

\section{Ataques indiscriminados}

Norma 11. Quedan prohibidos los ataques indiscriminados [CAI/CANI].

Norma 12. Son indiscriminados los ataques:

a) Que no están dirigidos contra un objetivo militar concreto.

b) En los que se emplean métodos o medios de combate que no pueden dirigirse contra un objetivo militar concreto.

c) En los que se emplean métodos o medios de combate cuyos efectos no sea posible limitar, como exige el derecho internacional humanitario.

$\mathrm{Y}$ que, en consecuencia, pueden alcanzar indistintamente, en cualquiera de tales casos, tanto a objetivos militares como a personas civiles o bienes de carácter civil [CAI/CANI].

Norma 13. Quedan prohibidos los ataques por bombardeo, cualesquiera que sean los métodos o medios utilizados, que traten como un objetivo militar único varios objetivos militares precisos y claramente separados, situados en una ciudad, un pueblo, una aldea u otra zona en la que haya una concentración análoga de personas civiles o bienes de carácter civil [CAI/CANI].

\section{Proporcionalidad en el ataque}

Norma 14. Queda prohibido lanzar un ataque cuando sea de prever que cause incidentalmente muertos y heridos entre la población civil, daños a bienes de 
carácter civil o ambas cosas, que sean excesivos en relación con la ventaja militar concreta y directa prevista $[\mathrm{CAI} / \mathrm{CANI}]$.

\section{Precauciones en el ataque}

Norma 15. Las operaciones militares se realizarán con un cuidado constante de preservar a la población civil, a las personas civiles y los bienes de carácter civil. Se tomarán todas las precauciones factibles para evitar, o reducir en todo caso a un mínimo, el número de muertos y heridos entre la población civil, así como los daños a bienes de carácter civil, que pudieran causar incidentalmente [CAI/CANI].

Norma 16. Las partes en conflicto deberán hacer todo lo que sea factible para verificar que los objetivos que prevén atacar son objetivos militares [CAI/CANI].

Norma 17. Las partes en conflicto deberán tomar todas las precauciones factibles en la elección de los medios y métodos de guerra para evitar, o reducir en todo caso a un mínimo, el número de muertos y de heridos entre la población civil, así como los daños a los bienes de carácter civil, que pudieran causar incidentalmente [CAI/CANI].

Norma 18. Las partes en conflicto deberán hacer todo lo que sea factible para evaluar si el ataque causará incidentalmente muertos o heridos entre la población civil, daños a bienes de carácter civil o ambas cosas, que sean excesivos en relación con la ventaja militar concreta y directa prevista [CAI/CANI].

Norma 19. Las partes en conflicto deberán hacer todo lo que sea factible para suspender o anular un ataque si se advierte que el objetivo no es militar o si es de prever que el ataque cause incidentalmente muertos o heridos entre la población civil, daños a bienes de carácter civil o ambas cosas, que sean excesivos en relación con la ventaja militar concreta y directa prevista [CAI/CANI].

Norma 20. Las partes en conflicto deberán dar aviso con la debida antelación y por medios eficaces de todo ataque que pueda afectar a la población civil, salvo si las circunstancias lo impiden [CAI/CANI].

Norma 21. Cuando se pueda elegir entre varios objetivos militares para obtener una ventaja militar similar, se optará por el objetivo cuyo ataque presente previsiblemente menos peligro para las personas civiles y los bienes de carácter civil [CAI/c.a. en CANI].

\section{Precauciones contra los efectos de los ataques}

Norma 22. Las partes en conflicto deberán tomar todas las precauciones factibles para proteger de los efectos de los ataques a la población civil y los bienes de carácter civil que estén bajo su control [CAI/CANI]. 
Norma 23. En la medida de lo factible, las partes en conflicto evitarán situar objetivos militares en el interior o cerca de zonas densamente pobladas $[\mathrm{CAI} / \mathrm{c}$.a. en CANI].

Norma 24. En la medida de lo factible, las partes en conflicto deberán alejar a las personas civiles y los bienes de carácter civil que estén bajo su control de la proximidad de objetivos militares [CAI/c.a. en CANI].

\section{PERSONAS Y BIENES ESPECIALMENTE PROTEGIDOS}

\section{Personal y bienes sanitarios y religiosos}

Norma 25. El personal sanitario exclusivamente destinado a tareas médicas será respetado y protegido en todas las circunstancias. Perderá su protección si, al margen de su función humanitaria, comete actos perjudiciales para el enemigo [CAI/CANI].

Norma 26. Queda prohibido castigar a alguien por realizar tareas médicas conformes con la deontología u obligar a una persona que ejerce una actividad médica a realizar actos contrarios a la deontología [CAI/CANI].

Norma 27. El personal religioso exclusivamente destinado a actividades religiosas será respetado y protegido en todas las circunstancias. Perderá su protección si, al margen de su función humanitaria, comete actos perjudiciales para el enemigo [CAI/CANI].

Norma 28. Las unidades sanitarias exclusivamente destinadas a tareas sanitarias serán respetadas y protegidas en todas las circunstancias. Perderán su protección si se utilizan, al margen de su función humanitaria, para cometer actos perjudiciales para el enemigo [CAI/CANI].

Norma 29. Los medios de transporte sanitarios exclusivamente destinados al transporte sanitario serán respetados y protegidos en todas las circunstancias. Perderán su protección si se utilizan, al margen de su función humanitaria, para cometer actos perjudiciales para el enemigo [CAI/CANI].

Norma 30. Quedan prohibidos los ataques directos contra el personal y los bienes sanitarios y religiosos que ostenten los signos distintivos estipulados en los Convenios de Ginebra de conformidad con el derecho internacional [CAI/CANI].

\section{Personal y bienes de socorro humanitario}

Norma 31. El personal de socorro humanitario será respetado y protegido [CAI/CANI]. 
Norma 32. Los bienes utilizados para las acciones de socorro humanitario serán respetados y protegidos [CAI/CANI].

\section{Personal y bienes de las misiones de mantenimiento de la paz}

Norma 33. Queda prohibido lanzar un ataque contra el personal y los bienes de las misiones de mantenimiento de la paz que sean conformes con la Carta de las Naciones Unidas, siempre que tengan derecho a la protección que el derecho internacional humanitario otorga a las personas civiles y los bienes de carácter civil [CAI/CANI].

\section{Periodistas}

Norma 34. Los periodistas civiles que realicen misiones profesionales en zonas de conflicto armado serán respetados y protegidos, siempre que no participen directamente en las hostilidades [CAI/CANI].

\section{Zonas protegidas}

Norma 35. Queda prohibido lanzar un ataque contra una zona establecida para proteger a los heridos, los enfermos y las personas civiles de los efectos de las hostilidades [CAI/CANI].

Norma 36. Queda prohibido lanzar un ataque contra una zona desmilitarizada de común acuerdo entre las partes en conflicto [CAI/CANI].

Norma 37. Queda prohibido lanzar un ataque contra una localidad no defendida $[\mathrm{CAI} / \mathrm{CANI}]$.

\section{Bienes culturales}

Norma 38. Las partes en conflicto deben respetar los bienes culturales:

A. En las operaciones militares se pondrá especial cuidado en no dañar los edificios dedicados a fines religiosos o caritativos, a la enseñanza, las artes o las ciencias, así como los monumentos históricos, a no ser que se trate de objetivos militares.

B. No serán atacados los bienes que tengan gran importancia para el patrimonio cultural de los pueblos, salvo en caso de necesidad militar imperiosa [CAI/CANI].

Norma 39. Queda prohibido utilizar bienes que tengan gran importancia para el patrimonio cultural de los pueblos para fines que pudieran exponerlos 
a su destrucción o deterioro, salvo en caso de necesidad militar imperiosa [CAI/CANI].

Norma 40. Las partes en conflicto deben proteger los bienes culturales:

A. Queda prohibido confiscar, destruir o dañar intencionadamente los establecimientos dedicados a fines religiosos o caritativos, a la enseñanza, las artes o las ciencias, así como los monumentos históricos y las obras artísticas o científicas.

B. Queda prohibida cualquier forma de robo, pillaje o apropiación indebida de bienes que tengan gran importancia para el patrimonio cultural de los pueblos, así como todo acto de vandalismo contra ellos [CAI/CANI].

Norma 41. La potencia ocupante debe impedir la exportación ilícita de bienes culturales de un territorio ocupado y devolver los bienes ilícitamente exportados a las autoridades competentes de ese territorio [CAI].

\section{Obras e instalaciones que contienen fuerzas peligrosas}

Norma 42. Se pondrá especial cuidado al atacar obras e instalaciones que contengan fuerzas peligrosas, a saber, presas, diques y centrales nucleares de energía eléctrica, así como otras instalaciones situadas en ellas o en sus proximidades, con el fin de evitar la liberación de esas fuerzas y las consiguientes pérdidas importantes entre la población civil [CAI/CANI].

\section{El medio ambiente natural}

Norma 43. Los principios generales sobre la conducción de las hostilidades se aplican al medio ambiente natural:

A. Ninguna parte del medio ambiente natural puede ser atacada, a menos que sea un objetivo militar.

B. Queda prohibida la destrucción de cualquier parte del medio ambiente natural, salvo que lo exija una necesidad militar imperiosa.

C. Queda prohibido lanzar ataques contra objetivos militares de los que quepa prever que causen daños incidentales al medio ambiente natural que sean excesivos en relación con la ventaja militar concreta y directa prevista [CAI/CANI].

Norma 44. Los métodos y medios de hacer la guerra deben emplearse teniendo debidamente en cuenta la necesidad de proteger y preservar el medio ambiente natural. En la conducción de las operaciones militares, han de tomarse todas las precauciones que sean factibles para no causar daños incidentales al medio ambiente o reducirlos, al menos, todo lo posible. La falta de certeza cien- 
tífica acerca de los efectos de ciertas operaciones militares sobre el medio ambiente no exime a las partes en conflicto de tomar tales precauciones $[\mathrm{CAI} / \mathrm{c} . \mathrm{a}$. en CANI].

Norma 45. Queda prohibido el empleo de métodos o medios de guerra concebidos para causar, o de los cuales quepa prever que causen daños extensos, duraderos y graves al medio ambiente natural. La destrucción del medio ambiente natural no puede usarse como arma $[\mathrm{CAI} / \mathrm{c}$.a. en $\mathrm{CANI}]$.

\section{MÉTODOS ESPECÍFICOS DE GUERRA}

\section{Prohibición de no dar cuartel}

Norma 46. Queda prohibido ordenar que no se dé cuartel, amenazar con ello al adversario o conducir las hostilidades en función de tal decisión [CAI/CANI].

Norma 47. Queda prohibido atacar a una persona cuando se reconozca que está fuera de combate. Está fuera de combate toda persona:

(a) que está en poder de una parte adversa;

(b) que no puede defenderse porque está inconsciente, ha naufragado o está herida o enferma; o

(c) que exprese claramente su intención de rendirse; siempre que se abstenga de todo acto hostil y no trate de evadirse [CAI/CANI].

Norma 48. Queda prohibido atacar, durante su descenso, a toda persona que se haya lanzado en paracaídas de una aeronave en peligro [CAI/CANI].

\section{Destrucción y confiscación de bienes}

Norma 49. Las partes en conflicto pueden confiscar el material militar perteneciente a un adversario como botín de guerra [CAI].

Norma 50. Queda prohibido destruir o confiscar los bienes de un adversario, a no ser que lo exija una necesidad militar imperiosa [CAI/CANI].

Norma 51. En los territorios ocupados:

(a) podrán confiscarse los bienes públicos muebles que puedan usarse para operaciones militares;

(b) los bienes públicos inmuebles deben administrarse de conformidad con la norma del usufructo; $y$

(c) los bienes privados deben respetarse y no pueden confiscarse; a no ser que una necesidad militar imperiosa exija la destrucción o confiscación de esos bienes [CAI].

Norma 52. Queda prohibido el pillaje [CAI/CANI]. 


\section{Hacer padecer hambre y acceso a la ayuda humanitaria}

Norma 53. Queda prohibido, como método de guerra, hacer padecer hambre a la población civil [CAI/CANI].

Norma 54. Queda prohibido atacar, destruir, sustraer o inutilizar los bienes indispensables para la supervivencia de la población civil [CAI/CANI].

Norma 55. Las partes en conflicto permitirán y facilitarán, a reserva de su derecho de control, el paso rápido y sin trabas de toda la ayuda humanitaria destinada a las personas civiles necesitadas que tenga carácter imparcial y se preste sin distinción desfavorable alguna $[\mathrm{CAI} / \mathrm{CANI}]$.

Norma 56. Las partes en conflicto deben garantizar la libertad de movimiento del personal humanitario autorizado, esencial para el ejercicio de sus funciones y que sólo podrá restringirse temporalmente en caso de necesidad militar imperiosa [CAI/CANI].

\section{Engaño}

Norma 57. Las estratagemas de guerra no están prohibidas, siempre que no infrinjan alguna norma del derecho internacional humanitario [CAI/CANI].

Norma 58. Queda prohibido hacer uso indebido de la bandera blanca de parlamento [CAI/CANI].

Norma 59. Queda prohibido hacer uso indebido de los emblemas distintivos estipulados en los Convenios de Ginebra [CAI/CANI].

Norma 60. Queda prohibido usar el emblema y el uniforme de las Naciones Unidas, a no ser que lo haya autorizado esta organización [CAI/CANI].

Norma 61. Queda prohibido hacer uso indebido de cualquier otro emblema internacionalmente reconocido [CAI/CANI].

Norma 62. Queda prohibido hacer uso indebido de las banderas o los emblemas militares, las insignias o los uniformes del adversario [CAI/c.a. en CANI].

Norma 63. Queda prohibido usar banderas o emblemas militares, insignias o uniformes de Estados neutrales o de otros Estados que no son partes en el conflicto $[\mathrm{CAI} / \mathrm{c}$.a. en CANI].

Norma 64. Queda prohibido concertar un acuerdo para suspender los combates con la intención de atacar por sorpresa al enemigo, confiado en ese acuerdo [CAI/CANI].

Norma 65. Queda prohibido matar, herir o capturar a un adversario valiéndose de medios pérfidos [CAI/CANI]. 


\section{Comunicación con el enemigo}

Norma 66. Los mandos podrán entablar entre ellos contactos no hostiles, que deberán basarse en la buena fe, a través de cualquier medio de comunicación $[\mathrm{CAI} / \mathrm{CANI}]$.

Norma 67. Los parlamentarios son inviolables [CAI/CANI].

Norma 68. Los mandos podrán tomar las precauciones necesarias para evitar que la presencia de un parlamentario sea perjudicial [CAI/CANI].

Norma 69. Los parlamentarios que aprovechen su posición privilegiada para cometer un acto contrario al derecho internacional y perjudicial para el adversario pierden su inviolabilidad [CAI/CANI].

\section{ARMAS}

Principios generales sobre el empleo de las armas

Norma 70. Queda prohibido el empleo de medios y métodos de guerra de tal índole que causen males superfluos o sufrimientos innecesarios [CAI/CANI].

Norma 71. Queda prohibido el empleo de armas de tal índole que sus efectos sean indiscriminados [CAI/CANI].

\section{Veneno}

Norma 72. Queda prohibido el empleo de veneno o de armas envenenadas [CAI/CANI].

\section{Armas biológicas}

Norma 73. Queda prohibido el empleo de armas biológicas [CAI/CANI].

\section{Armas químicas}

Norma 74. Queda prohibido el empleo de armas químicas [CAI/CANI].

Norma 75. Queda prohibido el empleo de sustancias antidisturbios como método de guerra $[\mathrm{CAI} / \mathrm{CANI}]$.

Norma 76. Queda prohibido el empleo de herbicidas como método de guerra si:

a) son de tal índole que están prohibidos como armas químicas;

b) son de tal índole que están prohibidos como armas biológicas;

c) están destinados a una vegetación que no es un objetivo militar; 
d) pueden causar incidentalmente muertos o heridos entre la población civil, daños a bienes de carácter civil, o ambas cosas, que sean excesivos en relación con la ventaja militar concreta y directa prevista; o

e) pueden causar daños extensos, duraderos y graves al medio ambiente natural $[\mathrm{CAI} / \mathrm{CANI}]$.

\section{Balas expansivas}

Norma 77. Queda prohibido el empleo de balas que se expanden o se aplastan fácilmente en el cuerpo humano [CAI/CANI].

\section{Balas explosivas}

Norma 78. Queda prohibido el empleo antipersonal de balas que explotan en el cuerpo humano [CAI/CANI].

\section{Armas cuyo efecto principal es lesionar mediante fragmentos no localizables}

Norma 79. Queda prohibido el empleo de armas cuyo efecto principal sea lesionar mediante fragmentos no localizables por rayos $\mathrm{X}$ en el cuerpo humano [CAI/CANI].

\section{Armas trampa}

Norma 80. Queda prohibido el empleo de armas trampa que estén de algún modo unidas o vinculadas a objetos o personas que gozan de una protección especial del derecho internacional humanitario o a objetos que pueden atraer a las personas civiles [CAI/CANI].

\section{Minas terrestres}

Norma 81. Cuando se empleen minas terrestres, se pondrá especial cuidado en reducir a un mínimo sus efectos indiscriminados [CAI/CANI].

Norma 82. Las partes en conflicto que empleen minas terrestres deberán registrar, en la medida de lo posible, su ubicación [CAI/c.a. en CANI].

Norma 83. Cuando cesen las hostilidades activas, las partes en conflicto que hayan empleado minas terrestres deberán retirarlas o hacerlas de algún otro modo inofensivas para la población civil, o facilitar su remoción [CAI/CANI]. 


\section{Armas incendiarias}

Norma 84. Si se emplean armas incendiarias, se pondrá especial cuidado en evitar que causen incidentalmente muertos o heridos entre la población civil, así como daños a bienes de carácter civil, o en reducir en todo caso a un mínimo estos efectos [CAI/CANI].

Norma 85. Queda prohibido el empleo antipersonal de armas incendiarias, a menos que no sea factible emplear un arma menos dañina para poner al adversario fuera de combate [CAI/CANI].

\section{Armas láser que causan ceguera}

Norma 86. Queda prohibido el empleo de armas láser específicamente concebidas, como su única o una más de sus funciones de combate, para causar ceguera permanente a la vista no amplificada [CAI/CANI].

\section{TRATO DEBIDO A LAS PERSONAS CIVILES O FUERA DE COMBATE}

\section{Garantías fundamentales}

Norma 87. Las personas civiles y las personas fuera de combate serán tratadas con humanidad [CAI/CANI].

Norma 88. En la aplicación del derecho internacional humanitario, está prohibido hacer distinciones de índole desfavorable basadas en la raza, el color, el sexo, la lengua, la religión o las creencias, las opiniones políticas o de otro género, el origen nacional o social, la fortuna, el nacimiento u otra condición, o cualquier otro criterio análogo [CAI/CANI].

Norma 89. Queda prohibido el homicidio [CAI/CANI].

Norma 90. Quedan prohibidos los actos de tortura, los tratos crueles e inhumanos y los atentados contra la dignidad personal, en particular los tratos humillantes y degradantes [CAI/CANI].

Norma 91. Quedan prohibidos los castigos corporales [CAI/CANI].

Norma 92. Quedan prohibidas las mutilaciones, las experimentaciones médicas o científicas o cualquier otra actuación médica no requerida por el estado de salud de la persona concernida y que no sea conforme a las normas médicas generalmente aceptadas [CAI/CANI]. 
Norma 93. Quedan prohibidas las violaciones y cualquier otra forma de violencia sexual [CAI/CANI].

Norma 94. Quedan prohibidas la esclavitud y la trata de esclavos en todas sus formas [CAI/CANI].

Norma 95. Queda prohibido el trabajo forzado no retribuido o abusivo [CAI/CANI].

Norma 96. Queda prohibido tomar rehenes [CAI/CANI].

Norma 97. Queda prohibida la utilización de escudos humanos [CAI/CANI].

Norma 98. Quedan prohibidas las desapariciones forzadas [CAI/CANI].

Norma 99. Queda prohibida la privación arbitraria de la libertad [CAI/CANI].

Norma 100. Nadie puede ser juzgado o condenado si no es en virtud de un proceso equitativo que ofrezca todas las garantías judiciales esenciales [CAI/CANI].

Norma 101. Nadie puede ser acusado o condenado por una acción u omisión que no constituía delito según el derecho nacional o internacional en el momento en que se cometió. Tampoco puede imponerse una pena mayor que la que era aplicable cuando se cometió la infracción penal [CAI/CANI].

Norma 102. Nadie puede ser condenado por un delito si no es basándose en la responsabilidad penal individual [CAI/CANI].

Norma 103. Quedan prohibidos los castigos colectivos [CAI/CANI].

Norma 104. Deben respetarse las convicciones y las prácticas religiosas de las personas civiles y de las personas fuera de combate [CAI/CANI].

Norma 105. En la medida de lo posible, se respetará la vida familiar [CAI/CANI].

\section{Combatientes y estatuto de prisionero de guerra}

Norma 106. Los combatientes deben distinguirse de la población civil cuando estén participando en un ataque o en una operación militar previa a un ataque. Si no lo hacen, no tienen derecho al estatuto de prisionero de guerra [CAI].

Norma 107. Los combatientes que son capturados mientras realizan actividades de espionaje no tienen derecho al estatuto de prisionero de guerra. No podrán ser juzgados ni condenados sin proceso previo [CAI].

Norma 108. Los mercenarios, tal y como están definidos en el Protocolo adicional I, no tienen derecho al estatuto de combatiente o de prisionero de guerra. No podrán ser juzgados ni condenados sin proceso previo [CAI]. 


\section{Heridos, enfermos y náufragos}

Norma 109. Cuando las circunstancias lo permitan, y en particular después de un combate, las partes en conflicto tomarán sin demora todas las medidas posibles para buscar, recoger y evacuar a los heridos, los enfermos y los náufragos sin distinción desfavorable alguna [CAI/CANI].

Norma 110. Los heridos, los enfermos y los náufragos recibirán cuanto antes, en la medida de lo posible, los cuidados médicos que exija su estado. No se hará entre ellos ninguna distinción que no esté basada en criterios médicos [CAI/CANI].

Norma 111. Las partes en conflicto tomarán todas las medidas posibles para proteger a los heridos, los enfermos y los náufragos contra los malos tratos y el pillaje de sus pertenencias [CAI/CANI].

\section{Personas fallecidas}

Norma 112. Cuando las circunstancias lo permitan, y en particular después de un combate, las partes en conflicto tomarán sin demora todas las medidas posibles para buscar, recoger y evacuar a los muertos sin distinción desfavorable alguna $[\mathrm{CAI} / \mathrm{CANI}]$.

Norma 113. Las partes en conflicto tomarán todas las medidas posibles para evitar que los muertos sean despojados. Está prohibido mutilar los cadáveres [CAI/CANI].

Norma 114. Las partes en conflicto harán todo lo posible para facilitar la repatriación de los restos mortales de las personas fallecidas, a solicitud de la parte a la que pertenecen o de sus familiares, y devolverán los efectos personales de los fallecidos [CAI].

Norma 115. Los muertos serán inhumados respetuosamente y sus tumbas respetadas y mantenidas debidamente [CAI/CANI].

Norma 116. Para facilitar la identificación de los muertos, las partes en conflicto deberán registrar toda la información disponible antes de inhumarlos y señalar la ubicación de las tumbas [CAI/CANI].

\section{Personas desaparecidas}

Norma 117. Las partes en conflicto tomarán todas las medidas factibles para averiguar lo acaecido a las personas dadas por desaparecidas a raíz de un conflicto armado y transmitirán a los familiares de éstas toda la información de que dispongan al respecto [CAI/CANI]. 


\section{Personas privadas de libertad}

Norma 118. Se proporcionará a las personas privadas de libertad alimentos, agua y ropa suficientes, así como un alojamiento y la asistencia médica convenientes [CAI/CANI].

Norma 119. Las mujeres privadas de libertad serán alojadas en locales separados de los ocupados por los hombres, excepto cuando estén recluidas con su familia como unidad familiar, y estarán bajo la vigilancia inmediata de mujeres [CAI/CANI].

Norma 120. Los niños privados de libertad serán alojados en locales separados de los ocupados por los adultos, excepto cuando estén recluidos con su familia como unidad familiar [CAI/CANI].

Norma 121. Las personas privadas de libertad deberán estar recluidas en locales alejados de la zona de combate, en condiciones higiénicas y saludables [CAI/CANI].

Norma 122. Queda prohibido el pillaje de las pertenencias de las personas privadas de libertad [CAI/CANI].

Norma 123. Deberán registrarse los datos personales de las personas privadas de libertad [CAI/CANI].

Norma 124:

A. En los conflictos armados internacionales, se facilitará al CICR el acceso, con regularidad, a todas las personas privadas de libertad, con el fin de verificar las condiciones de detención y de restablecer el contacto entre esas personas y sus familiares [CAI].

B. En los conflictos armados no internacionales, el CICR puede ofrecer sus servicios a las partes en conflicto para visitar a todas las personas privadas de libertad por razones relacionadas con el conflicto, con el fin de verificar las condiciones de detención y de restablecer el contacto entre esas personas y sus familiares [CANI].

Norma 125. Las personas privadas de libertad estarán autorizadas a mantener correspondencia con sus familiares, con tal que se respeten las legítimas condiciones concernientes a su frecuencia y a la necesidad de censura por parte de las autoridades [CAI/CANI].

Norma 126. Los internados civiles y las personas privadas de libertad en relación con un conflicto armado no internacional serán autorizados, en la medida de lo posible, a recibir visitas, en particular de sus parientes cercanos [CAI/CANI]. 
Norma 127. Deberán respetarse las convicciones personales y las prácticas religiosas de las personas privadas de libertad [CAI/CANI].

Norma 128:

A. Los prisioneros de guerra serán liberados y repatriados sin demora cuando hayan cesado las hostilidades activas [CAI].

B. Los internados civiles serán puestos en libertad tan pronto como dejen de existir los motivos de su internamiento, pero, en todo caso, lo antes posible tras el fin de las hostilidades activas [CAI].

C. Las personas privadas de libertad en relación con un conflicto armado no internacional serán liberadas tan pronto como dejen de existir los motivos por los cuales fueron privadas de su libertad [CANI].

Si las personas mencionadas están cumpliendo una condena legalmente impuesta o si se han instruido diligencias penales contra ellas, podrá mantenerse su privación de libertad.

\section{Desplazamientos y personas desplazadas}

Norma 129:

A. Las partes en un conflicto armado internacional no pueden deportar o trasladar a la fuerza a toda la población civil de un territorio ocupado, o a parte de ella, a no ser que lo exijan la seguridad de la población civil o razones militares imperiosas [CAI].

B. Las partes en un conflicto armado no internacional no pueden ordenar el desplazamiento, total o parcial, de la población civil por razones relacionadas con el conflicto, a no ser que lo exijan la seguridad de la población civil o razones militares imperiosas [CANI].

Norma 130. Los Estados no pueden deportar o trasladar partes de su población civil a un territorio ocupado por ellos [CAI].

Norma 131. En caso de desplazamiento, se tomarán todas las medidas posibles para que las personas afectadas sean acogidas en condiciones satisfactorias de alojamiento, higiene, salubridad, seguridad y alimentación, y para que no se separen los miembros de una misma familia [CAI/CANI].

Norma 132. Las personas desplazadas tienen derecho a regresar voluntariamente a su hogar o a su lugar habitual de residencia, tan pronto como dejen de existir las razones que motivaron su desplazamiento [CAI/CANI].

Norma 133. Deberán respetarse los derechos de propiedad de las personas desplazadas [CAI/CANI]. 


\section{Otras personas especialmente protegidas}

Norma 134. Deberán respetarse las necesidades específicas de las mujeres afectadas por los conflictos armados en materia de protección, salud y asistencia [CAI/CANI].

Norma 135. Los niños afectados por los conflictos armados tienen derecho a un respeto y protección especiales [CAI/CANI].

Norma 136. Las fuerzas armadas o los grupos armados no deberán reclutar niños [CAI/CANI].

Norma 137. No se permitirá que los niños participen en las hostilidades [CAI/CANI].

Norma 138. Los ancianos, los inválidos y los enfermos mentales afectados por los conflictos armados tienen derecho a un respeto y protección especiales $[\mathrm{CAI} / \mathrm{CANI}]$.

\section{APLICACIÓN \\ Respeto del derecho internacional humanitario}

Norma 139. Las partes en conflicto deberán respetar y hacer respetar el derecho internacional humanitario por sus fuerzas armadas, así como por otras personas y agrupaciones que actúen de hecho siguiendo sus instrucciones o bajo su dirección o control [CAI/CANI].

Norma 140. La obligación de respetar y hacer respetar el derecho internacional humanitario no depende de la reciprocidad [CAI/CANI].

Norma 141. Cuando sea necesario, los Estados pondrán asesores jurídicos a disposición de los jefes militares para que los aconsejen, al nivel adecuado, sobre la aplicación del derecho internacional humanitario [CAI/CANI].

Norma 142. Los Estados y las partes en conflicto deberán impartir cursos de formación en derecho internacional humanitario a sus fuerzas armadas [CAI/CANI].

Norma 143. Los Estados deberán promover la enseñanza del derecho internacional humanitario entre la población civil [CAI/CANI].

\section{Medidas para hacer respetar el derecho internacional humanitario}

Norma 144. Los Estados no alentarán las violaciones del derecho internacional humanitario por las partes en un conflicto armado. En la medida de lo posible, deberán ejercer su influencia para hacer que cesen esas violaciones [CAI/CANI]. 
Norma 145. Cuando no están prohibidas por el derecho internacional, las represalias bélicas están sujetas a condiciones estrictas [CAI].

Norma 146. Quedan prohibidas las represalias bélicas contra las personas protegidas por los Convenios de Ginebra [CAI].

Norma 147. Quedan prohibidas las represalias contra los bienes protegidos por los Convenios de Ginebra y la Convención de La Haya para la Protección de los Bienes Culturales [CAI].

Norma 148. Las partes en un conflicto armado no internacional no tienen derecho a recurrir a represalias bélicas. Quedan prohibidas otras contramedidas contra personas que no participan o han dejado de participar directamente en las hostilidades [CANI].

\section{Responsabilidad y reparaciones}

Norma 149. Un Estado es responsable de las violaciones del derecho internacional humanitario que le son imputables, en particular:

(a) las violaciones cometidas por sus órganos, incluidas sus fuerzas armadas;

(b) las violaciones cometidas por personas o entidades autorizadas a ejercer prerrogativas de su autoridad gubernativa;

(c) las violaciones cometidas por personas o grupos que actúan de hecho obedeciendo sus instrucciones o bajo su dirección o control; y

(d) las violaciones cometidas por personas o grupos privados que él reconoce y acepta como comportamiento propio.

[CAI/CANI]

Norma 150. El Estado responsable de violaciones del derecho internacional humanitario está obligado a reparar íntegramente la pérdida o la lesión causada [CAI/CANI].

\section{Responsabilidad individual}

Norma 151. Las personas que cometen crímenes de guerra son penalmente responsables de ellos [CAI/CANI].

Norma 152. Los jefes y otros mandos superiores son penalmente responsables de los crímenes de guerra cometidos en cumplimiento de sus órdenes [CAI/CANI].

Norma 153. Los jefes y otros mandos superiores son penalmente responsables de los crímenes de guerra cometidos por sus subordinados si sabían, o deberían haber sabido, que éstos iban a cometer o estaban cometiendo tales crímenes 
y no tomaron todas las medidas razonables y necesarias a su alcance para evitar que se cometieran o, si ya se habían cometido, para castigar a los responsables [CAI/CANI].

Norma 154. Los combatientes tienen la obligación de desobedecer una orden que es manifiestamente ilícita [CAI/CANI].

Norma 155. La obediencia a la orden de un superior no exime a un subordinado de su responsabilidad penal si sabía que el acto ordenado era ilícito o debería haberlo sabido porque su ilicitud era manifiesta [CAI/CANI].

\section{Crímenes de guerra}

Norma 156. Las violaciones graves del derecho internacional humanitario constituyen crímenes de guerra [CAI/CANI].

Norma 157. Los Estados tienen derecho a conferir a sus tribunales nacionales jurisdicción universal en materia de crímenes de guerra [CAI/CANI].

Norma 158. Los Estados deberán investigar los crímenes de guerra presuntamente cometidos por sus ciudadanos o sus fuerzas armadas, así como en su territorio, y encausar, si procede, a los imputados. Deberán asimismo investigar otros crímenes de guerra que sean de su competencia y encausar, si procede, a los imputados [CAI/CANI].

Norma 159. Cuando hayan cesado las hostilidades, las autoridades en el poder se esforzarán por conceder la amnistía más amplia posible a quienes hayan participado en un conflicto armado no internacional o a las personas privadas de libertad por razones relacionadas con el conflicto armado, salvo a las personas sospechosas o acusadas de haber cometido crímenes de guerra, o que estén condenadas por ello [CANI].

Norma 160. Las leyes de prescripción no se aplican a los crímenes de guerra $[\mathrm{CAI} / \mathrm{CANI}]$.

Norma 161. Los Estados se esforzarán en cooperar todo lo posible entre ellos con el fin de facilitar la investigación de los crímenes de guerra y el enjuiciamiento de los imputados [CAI/CANI]. 
y no tomaron todas las medidas razonables y necesarias a su alcance para evitar que se cometieran o, si ya se habían cometido, para castigar a los responsables [CAI/CANI].

Norma 154. Los combatientes tienen la obligación de desobedecer una orden que es manifiestamente ilícita [CAI/CANI].

Norma 155. La obediencia a la orden de un superior no exime a un subordinado de su responsabilidad penal si sabía que el acto ordenado era ilícito o debería haberlo sabido porque su ilicitud era manifiesta [CAI/CANI].

\section{Crímenes de guerra}

Norma 156. Las violaciones graves del derecho internacional humanitario constituyen crímenes de guerra [CAI/CANI].

Norma 157. Los Estados tienen derecho a conferir a sus tribunales nacionales jurisdicción universal en materia de crímenes de guerra [CAI/CANI].

Norma 158. Los Estados deberán investigar los crímenes de guerra presuntamente cometidos por sus ciudadanos o sus fuerzas armadas, así como en su territorio, y encausar, si procede, a los imputados. Deberán asimismo investigar otros crímenes de guerra que sean de su competencia y encausar, si procede, a los imputados [CAI/CANI].

Norma 159. Cuando hayan cesado las hostilidades, las autoridades en el poder se esforzarán por conceder la amnistía más amplia posible a quienes hayan participado en un conflicto armado no internacional o a las personas privadas de libertad por razones relacionadas con el conflicto armado, salvo a las personas sospechosas o acusadas de haber cometido crímenes de guerra, o que estén condenadas por ello [CANI].

Norma 160. Las leyes de prescripción no se aplican a los crímenes de guerra $[\mathrm{CAI} / \mathrm{CANI}]$.

Norma 161. Los Estados se esforzarán en cooperar todo lo posible entre ellos con el fin de facilitar la investigación de los crímenes de guerra y el enjuiciamiento de los imputados [CAI/CANI]. 